\title{
LA EDUCACIÓN FÍSICA COMO IDEOLOGIA DEL PODER: LA CONSTRUCCIÓN DE LAS CREENCIAS PEDAGÓGICAS EN TORNO LAS ENSEÑANZAS ESCOLARES DEL CUERPO
}

\author{
Miguel Vicente Pedraz \\ Profesor titular adscrito al Departamento de Educación Física \\ Universidad de León \\ León, España
}

Recibido 9-I-2009 • Aceptado 13-IV-2009 • Corregido 30-V-2009

\begin{abstract}
Resumen: Este artículo aborda el contenido político $e$ ideológico de la Educación Física. Una materia escolar cuyo discurso didáctico, amparado en la verosimilitud que expresa la relación técnica entre medios y fines (pedagógicos), ofrece una imagen de neutralidad y de asepsia ideológica que las representaciones sociales dominantes del cuerpo parecen corroborar: el cuerpo entendido como estructura orgánica y anatómica. La creencia en la sustancialidad del cuerpo y de la propia disciplina académica ha ido configurando toda una serie de estructuras pedagógicas y, asimismo, todo un cuerpo argumentativo y de prácticas que hacen de ella una disciplina prácticamente infranqueable a la crítica, salvo en cuestiones superficiales de su puesta en escena, que da lugar a situaciones educativas paradójicas, tal vez inadmisibles en otras disciplinas $y$ contextos. Con estos supuestos, el objetivo del artículo es poner de relieve algunos de los mecanismos de construcción de estas creencias, identificar las relaciones de poder que sustentan dichos mecanismos y cuestionar la practicidad del curriculum que como resultado ofrece el discurso técnico legitimado.
\end{abstract}

Palabras clave: Educación Física, ideología, poder, subjetividad.

\section{Introducción: creencias pedagógicas, legitimidad y dominación cultural en la educación fisica}

Algunas de las viejas discusiones epistemológicas y la búsqueda de reconocimiento pedagógico, que en los años ochenta ocupaban en España (y en su contexto próximo) un lugar de privilegio en el debate de la Educación Física, parecen haber cedido definitivamente en favor de debates de carácter más doméstico, a menudo destinados al consumo masivo de los profesores. Los discursos que pugnaban por la consideración científica de la disciplina, a veces con mucha vehemencia pero con escasa consistencia argumentativa, no constituyen hoy un ámbito de preocupaciones significativo: cuestiones entonces muy frecuentes comola del estatus epistemológico, los referentes teóricos, el paradigma al que debía o podía adscribirse y, sobre todo, la identificación o definición de su objeto de estudio -cuestiones con los que además se esperaba legitimar la materia escolar- 


\begin{abstract}
This article addresses the political and ideological dimension of physical education. The didactic discourse more specific of physical education, as a school subject, relies upon the technical relationship between pedagogical means and ends, and, therefore, offers a rather neutrally ideological image of those social representations that most define the body as an organic and anatomic structure. The belief in the substantiality of the body and in physical education as an academic discipline itself has shaped a large series of educational structures as well as a whole body of arguments and practices, all meant to convert physical education in a discipline virtually above any attempt of criticism, except for certain superficial matters, rather paradoxical and, probably, hardly acceptable in other disciplines and educational contexts. With these assumptions, the objective of the article is to discuss some of the mechanisms of construction of these beliefs, to identify the power relations that sustain these mechanisms and to question the deficiency of practical sense of the curriculum that as a result legitimizes the technical discourse.
\end{abstract}

Key words: Physical education, ideology, power, subjectivity. parecen suscitar en este momento muy poco entusiasmo investigador. Al menos muy poco en comparación con el interés que despierta la tecnología didáctica, siempre resuelta a satisfacer las necesidades prácticas de los profesores avocados a la inmediatez de tener que enseñar algo a los escolares y de enseñarlo bien.

En campoeste contexto, más allá de las disputas entre sensibilidades y concepciones didácticas diferentes que, en ocasiones, han dado lugar a modelos y paradigmas de Educación Física que entre sí se han considerado antagónicos, la mayoría de los trabajos del área han apelado y apelan de manera recurrente al cambio, la innovación, la transformación, la superación, la alternativa curricular, etc., respecto de lo que, sin excepción, todos los autores denominan Educación Física tradicional; algo que sin duda pone de manifiesto, además del entusiasmo didáctico, el celo innovador y también, en parte, la percepción que muchos tienen del agotamiento pedagógico de la vieja materia.

Pues bien, la oportunidad política y administrativa de introducir en el debate académico de la Educación Física algunos de los modelos enseñanza desarrollados fruto de esas corrientes de investigación didáctica, $\mathrm{y}$, eventualmente, la posibilidad de ponerlos en práctica en los programas de Educación Física escolar -con mejor o peor fortuna y pervivencia-, han supuesto, paradójicamente, mayor impulso legitimador para la Educación Física escolar que los antiguos debates sobre el objeto de estudio: desde luego, mayor reconocimiento que los discursos sobre los fundamentos científicos de la materia y, también, mayor estabilidad curricular que la búsqueda del estatus epistemológico de antaño. Tal vez, la razón de ello estribe en la propia naturaleza de la producción didáctica cuya funcionalidad instrumental y verosimilitud técnica ofrece una imagen de practicidad y de "apego a la realidad" -sustentada en el poder de convicción que despliega la visualización de la relación mecánica entre medios y fines-, lo cual ha ido impregnando 
la opinión pedagógica y obrando tercamente al servicio del reconocimiento político y social de un estado de cosas (curriculares) que ya aparece como natural y por ello, también, como indiscutible.

Sin embargo, dichas líneas de investigación didáctica y el discurso técnico en el que se apoyan -incluso cuando se postulan como innovadoras o alternativas- en lugar de asumir una perspectiva crítica tanto de alcance particular como global del ejercicio educativo y en vez de atender a los grandes problemas y discusiones que ha planteado y sigue planteando la Pedagogía, se han resignado a elaborar sucesivas propuestas en las que ha primado el acopio de actividades novedosas sobre la modernización de las estructuras y las mentalidades pedagógicas.

En estas propuestas ha imperado la proliferación de estrategias sobre la adecuación de los métodos y los contenidos a la nueva realidad escolar y, sobre todo, a la nueva realidad social. Es decir, han prevalecido las formas sobre el fondo según unos criterios de banal eficiencia que, según la opinión del autor de este artículo, han obstaculizado toda posibilidad de conformar una materia escolar de carácter emancipador orientada al desarrollo de capacidades críticas y deliberativas respecto de los usos del cuerpo con una significación vital y una utilidad existencial más allá de la actividad lúdica complaciente.

Desde el punto de vista de este artículo, las propuestas de las líneas de investigación didáctica antes referidas han obrado como dispositivos ideológicos que han contribuido muy estrechamente al mantenimiento de las relaciones de poder.

Pues bien, lo que a este respecto se plantea es profundizar en el proceso de configuración académica de la Educación Física prestando atención no tanto a la sucesión de los hechos (históricos) en sí mismos, como a la elaboración, difusión y consolidación de algunos de los principios y categorías, concepciones y representaciones que definen la materia y, a la vez, le dan el sentido y la legitimidad pedagógicos que posee. La tarea fundamental consiste en identificar las principales creencias que sostienen el discurso establecido de la Educación Física y las supuestas verdades (positivas), en torno a los cuales se constituyen y justifican los paradigmas dominantes en la materia. Esto es, se pretende descubrir en qué medida las nociones más indiscutibles que la definen se formulan y se desarrollan como inferencias derivadas de una practicidadconstatable-tal como lo postula la didáctica de la Educación Física-o si, por el contrario, son constructos estructurantes, esquemas subjetivos y de saber previos o preconceptos, que tienen la función de demarcar arbitrariamente el alcance y los límites de sus competencias.

En todo caso, se trata de comprobar hasta qué punto tales constructos pueden ser considerados como dispositivos ideológicos y tópicos arraigados -lugares comunes- que determinan de antemano -o sólo a posteriori- el universo posible del discurso y de la práctica, independientemente de una pertinencia pedagógica objetivable en términos de proyecto y fines educativos plausibles.

Se señala aquí que se adopta una perspectiva sociogenética de corte constructivista, según la cual toda realidad social se concibe como un producto histórico, en el entendimiento de que se hace un tipo de análisis que pone el acento en la interdependencia de discursos, instituciones e individuos entre sí en la producción de la realidad. Esta, lejos de considerarse externa a los sujetos -los cuales la "habitan"-e, incluso, lejos de ser considerada como el producto de los proyectos de los sujetos individuales, se entiende como una configuración: una forma específica de interrelación - tejida sobre esquemas de percepción y sensibilidad, conscientes o no- que liga a unos individuos con otros y de la que los propios individuos y las estructuras internas de su personalidad -los sujetos- son parte de la producción.

A este respecto, aunque serán dispersas y hasta deliberadamente diversas las referencias teóricas, como herramientas 
conceptuales básicas que sirvan a los propósitos de este artículo se toma de Elias (1978, 1989, 1990), además de la idea de configuración, la noción de poder como relación asimétrica de interdependencia. De Bourdieu (1988), la dimensión simbólica del orden social y con ella las nociones de capital simbólico, social y cultural y su relación con las nociones de campo y habitus, además de algunas de sus formulaciones a propósito del sistema escolar como agencia reproductora de las desigualdades sociales. De Berger y Luckmann (2003), la noción de universo simbólico y su relación con los procesos de institucionalización y legitimación. De Foucault (1979, 1999), las nociones de esquemas o regímenes de verdad, tecnologías del yo, etc. De la teoría crítica, la idea de que el mundo social y sus objetos se construyen a partir de preconstrucciones pasadas que son reproducidas, apropiadas, desplazadas y transformadas al tiempo que se inventan otras; asimismo, el concepto de herencia social, según el cual una vez que esta está sedimentada y objetivada en una exterioridad, constriñe de modo ineludible las producciones futuras que, no obstante, no están prefiguradas ni cerradas.

Se hace finalmente una precisión metodológica. Aunque no hay intención de hacer una escala jerárquica de los tópicos que operan en la justificación y legitimación de la Educación Física escolar -los cuales, desde el punto de vista de este artículo, se configuran en forma reticular o circular donde creencias de carácter más doméstico alimentan el discurso pericial y viceversa-, como recurso expositivo, trataremos de establecer una secuencia no tanto por el grado de importancia como por el nivel de generalidad.

Sirva a este respecto poner de relieve el declarado interés historiográfico y epistemológico, así como la postura constructivista, para comenzar la indagación por el que se considera más general -y tal vez más crucial- de cuantos tópicos encarna el discurso de la Educación Física: el tópico sustancialista del que, posiblemente, derivan todos los demás y según el cual la disciplina sería el resultado de un "proyecto natural" que habría emanado de unas necesidades objetivas, naturales y sustanciales que harían de la materia una disciplina inexcusable.

En segundo lugar, en un nivel intermedio de generalidad, será analizado el que en este artículo se denomina tópico de la funcionalidad práctica de la materia, funcionalidad tanto para los sujetos como para la sociedad. Este consiste, por una parte, en la capitalización intensiva de propiedades formativas y reformativas por parte de la Educación Física y, por otra, la des-subjetivación del cuerpo: la configuración de un sujeto pedagógico apto para ser educado físicamente de acuerdo con los postulados que el discurso técnico establece como posibles y legítimos.

En último lugar, en el nivel más concreto, se plantean algunos tópicos que, bajo el apelativo de "la ilusión didáctica", se configuran como creencias de carácter doméstico, creencias que operan en el ámbito en el que los profesores de Educación Física declaran y definen su quehacer diario y que, por una parte, sirven para justificar profesionalmente la tarea que realizan y, por otra, alimentan el discurso técnico proveyéndole de la materia prima de análisis: la experiencia pedagógica, evidentemente, tamizada por las propias creencias profesionales en las que dicha experiencia acontece.

\section{Superar el sustancialismo y el historicismo evolucionista}

El tópico sustancialista, como se ha apuntado, consiste en la consideración de la disciplina como el resultado de un "proyecto natural" que habría emanado de unas necesidades objetivas, naturales, sustanciales y, por lo demás, preexistentes de la educación del cuerpo; unas necesidades que explicarían su temprana aparición como un acontecimiento antropológico $\mathrm{y}$, asimismo, las sucesivas modalidades de acuerdo con las distintas circunstancias culturales. Se 
trata de una consideración que se adhiere a la historicidad de la disciplina -incluso enfatiza su condición evolutiva- pero que concibe el proceso histórico de manera lineal, unidireccional y finalista, además de perpetuo, sobre la creencia positivista de la permanencia (sustantiva) del cuerpo y la confianza en el desarrollo infinito de la historia y de sus objetos. A este respecto, el relato histórico convencional de la Educación Física traspone a épocas pretéritas y a civilizaciones clásicas escenas típicas de la educación física actual y viceversa, con lo que, además de afirmar su universalidad, provee a la disciplina de una procedencia prestigiosa que le confiere legitimidad como forma de intervención pedagógica. A la vez, y por añadidura, no concibe la escuela o, al menos, la sociedad, sin una institución formativa que atienda a tan indiscutibles y perennes necesidades de aprendizaje corporal.

Resulta clarificador de esta cuestión lo que plantea Elias $(1978,1990)$, uno de referentes del constructivismo, entre cuyas preocupaciones epistemológicas más recurrentes figura el mito sustancialista asociado a los usos comunes del lenguaje. Según él, el sustancialismo -que, como ya expresara Wittgenstein (1994), consiste en la búsqueda de una sustancia que responda a un sustantivo-determina el hecho de considerar a priori que tras las palabras que empleamos existen realidades perfectamente definidas, sustancias, cosas visibles y tangibles (Elias, 1978), realidades, en cierto modo, atemporales o preexistentes que, por lo demás, son independientes de la conciencia. El sustancialismo, que en sus versiones menos elaboradas funciona como un realismo ingenuo, se abre paso en la práctica como una corriente anti-histórica en la medida en que da carta de naturaleza "natural" a todo lo nombrado -y, se diría, que sólo a lo nombrado-, donde el lenguaje cumpliría el papel de fedatario de una realidad que, con matices, tiende a ser considerada como "dada" y por lo demás dicotómica: sujeto/objeto, individuo/sociedad, cuerpo/espíritu, físico/social, real/imaginario, etcétera.
El sustancialismo responde a una concepción, en general, de corte funcionalista, según la cual las realidades -también las sociales- estarían sometidas a un ajuste orgánico, cuasimecánico, cuyo funcionamiento estaría asegurado por una especie de relación solidaria entre los distintos elementos que la componen (conceptos, saberes, creencias, representaciones, cosas, sujetos, grupos de sujetos, instituciones, etcétera); consiste en la proyección que sobre el nivel institucional y sobre los fines colectivos suele hacerse de esa especie de armonía sustancial que la experiencia individual o el sentido común percibe en las realidades individuales y, sobre todo, orgánicas, tales como el sistema biológico, cuyas acciones parecen siempre orientadas según cierto sentido finalista y determinista al equilibrio del propio sistema: la realidad tiende a ser lo que "es", y viceversa, es lo que "tiende a ser".

Contra esta concepción, Elias (1989) propone utilizar precisamente las armas de la historia y, en particular, la sociogénesis y la psicogénesis de la cultura, las cuales demuestran la aparición relativamente tardía de entidades tan aparentemente incuestionables como la imagen del hombre por parte de la sociedad, así como las concepciones familiares e, incluso, las nociones de sociedad o individuo, tiempo, cuerpo, etc., -todas ellas elaboradas sobre una problemática típicamente occidental y moderna-. El autor no sólo pone de relieve el carácter contingente de la realidad sino que, sobre todo, advierte de las trampas que la historiografía de corte evolucionista puede tender: especialmente, la trampa de la cosmovisión finalista de la civilización según la cual el transcurso del tiempo y, con él, la sucesión de los acontecimientos estarían orientados a un fin predeterminado que, de algún modo, sería la resultante de aquello que las cosas por sí mismas o por naturaleza, por su sustancia, "tienden a ser". En este sentido, para él, el devenir histórico de la humanidad se origina en una multiplicidad de proyectos, pero sin 
proyecto y sin destino: "nacido de planes, pero no planeado; movido por fines, pero sin finalidad" (Elias, 1990, p. 84).

Pues bien, la consideración más común de la Educación Física incurre precisamente en esta trampa historicista que a la postre, según se verá, ampara cierta clase de discurso técnico, sobre todo el didáctico, en cuya verosimilitud encuentra legitimidad pedagógica. En virtud de la relación solidaria y armónica de todo sistema, la Educación Física como institución, pese a no estar exenta de desequilibrios, tendería al reequilibrio o "normalización", con lo que su proceso de transformación histórica se entendería como una evolución funcional en sentido estricto; o sea, como un paulatino equilibrio "natural" de los medios y de los fines educativos del cuerpo que se va dando a lo largo del tiempo. Bajo esta perspectiva, las distintas modalidades o versiones que en cada cultura, en cada civilización o en cada momento histórico hayan podido tener lugar, no serían sino simples adaptaciones al contexto -o la mera modernización de prácticas- de algo que en el fondo, en su esencia, tendría la misma sustancia y habría estado ya presente -prefigurado- en el pasado remoto.

Lo mismo sucedería a la disciplina en su estado actual; en este caso, las propias connotaciones de la noción de equilibración "natural" y de ajuste de lo "dado" vendrían a justificar y legitimar la disciplina tal como se la conoce en tanto que la más propicia, técnicamente hablando, de acuerdo con las necesidades sociales actuales y los medios técnicos disponibles. Es justamente en este marco teórico donde el análisis general de la materia académica coincide más estrechamente con las concepciones sustancialistas de la realidad en el sentido de que la sustancia o esencia contenida en "educar el cuerpo" no sólo sirve para explicar, sino también para justificar el estado de cosas actuales, por cuanto el sentido íntimo de la locución "educar el cuerpo" ya contiene todas las posibilidades de ser (todos los paradigmas, todas las modalidades culturales, todas las singularidades históricas, todas las intencionalidades pedagógicas, etcétera) de la Educación Física en su paulatina evolución (técnica); también, por supuesto, la modalidad contemporánea, cuyo grado de racionalidad -supuestamente avalado por las disciplinas científicas que la asisten en la producción de sus prácticas- bastaría para certificar su pertinencia pedagógica, tiene por esto un carácter indiscutible.

No cabe duda de la credibilidad que es capaz de generar el sustancialismo y, con él, el historicismo evolucionista cuya simplicidad conceptual permite establecer una línea de progresión diáfana entre lo que la Educación Física fue, lo que es y lo que debe ser. Una línea de progresión y continuidad en el tiempo que, además, le imprime cierta aureola de inevitabilidad que la hace concurrente con las percepciones originadas en el sentido común. No en vano el marco teórico en el que se inscribe es el objetivismo social, según el cual todas las instituciones aparecen como dadas, inalterables en su esencia y evidentes por sí mismas, de la misma manera que, a título de ejemplo, considerando la socialización del lenguaje, este se aparece al niño que lo aprende como inherente a la naturaleza de las cosas, incapaz de captar su convencionalidad (Berger y Luckmann, 2003).

Sin embargo, y contra esa concepción, hay que hacer notar que resulta en extremo sospechoso la ausencia de interrupciones, saltos cualitativos, retrocesos, cruzamientos, vacíos, intentos fallidos, etc. en el relato histórico de la Educación Física al uso, lo cual pone sobre aviso acerca de la posibilidad de que dicho relato haya sido elaborado de delante hacia atrás - del presente al pasado-, lo que ha permitido subrayar los elementos comunes, dentro de esa línea de progresión histórica imaginada, pero que ha renunciado a señalar los elementos -probablemente más numerosos y de mayor calado- de discrepancia. Así, por ejemplo, entre la escena de un patio escolar del siglo XX en el que un profesor enseña a saltar en longitud a sus alumnos y una escena de la Atenas del siglo de IV a.C. en el que un paidotriba 
supervisa la preparación de un gimnasta o de un atleta, se pone de relieve lo que en el plano estrictamente técnico hace comparables una y otra acción -enfatizando, pues, lo invariable que como acto comunicativo posee la acción de enseñar- independientemente de los significados, de los propósitos, de las intenciones, del sentido cultural de ambos actos, de la trascendencia política, del contexto institucional, por no mencionar la abismal distancia que separa a ambas situaciones en cuanto al tipo racionalidad antropológica, sociológica y epistemológica sobre la que operan; todo lo cual revelaría las profundas diferencias entre una y otra "sustancia" y, con ello, la inconsistencia que supone vincular ambos hechos en la narración histórica de la materia.

Obviamente, y tal vez esto sea lo más importante de la cuestión que se está tratando, al descartar todos los escollos culturales, sociales, políticos, ideológicos, epistemológicos, etc., la explicación historicista del desarrollo de la materia ofrece una imagen de continuidad "natural", sin comienzo pero con final predeterminado -la antihistoria- que escamotea el debate público a propósito de las condiciones de su producción; escamotea, especialmente, el debate a propósito de las luchas simbólicas que se han librado en la configuración de las distintas tradiciones pedagógicas del cuerpo e impide, en última instancia, conocer y determinar críticamente los elementos que han operado como dispositivos de selección de prácticas, de contenidos, de objetivos, de medios, de instituciones, de ideologías políticas, de disciplinas proveedoras de saberes, etc. y, en definitiva, en la definición de la Educación Física escolar.

Es aquí donde la crítica de Elias (1978, 1989) al sustancialismo y al historicismo evolucionista pone al alcance de la mano algunas reflexiones que podrían servir de ayuda en el análisis genealógico de la Educación Física como materia escolar. Frente a la concepción de la realidad social como un precipitado cuasinatural como el que ampara el sustancialismo, Elias (1989) aborda la cuestión de la génesis de las instituciones desde una perspectiva constructivista; es decir, una perspectiva según la cual toda realidad se concibe como conjunto de producciones genuinas de una cierta cultura y de un cierto tiempo, aunque evidentemente como resultado de previas construcciones históricas. Sin embargo, y a diferencia del historicismo, la perspectiva constructivista pone el énfasis en las acciones de los actores individuales y colectivos concretos en situaciones concretas, de modo que la pluralidad de intenciones, de significados, de formas de apropiación de las preconstrucciones pasadas, etc. da lugar a un conjunto heterogéneo de producciones sociales que, al no surgir necesariamente de una voluntad clara, ni de una naturaleza dada, tiende a escapar al control de los diferentes actores implicados (y de la propia historia). Entre otras, una característica fundamental común a todos los constructivismos -ya sea el del pionero Elias (1978), el constructivismo estructuralista de Bourdieu (1988) o el fenomenológico de Berger y Luckmann (2003) - es el énfasis en la dimensión simbólica de la realidad y, en este sentido, la problematización de las categorías objetivo-subjetivo y lo que ello supone en la consideración tanto del sujeto como de las interacciones entre los diferentes sujetos y entre estos y las instituciones en el proceso de representación-construcción del mundo. Y lo que ello implica, a diferencia de los modelos sistémicos y funcionalistas, es que se hace descansar el significado y la pervivencia más o menos armónica de la realidad social y de cada una de sus instituciones no en las nociones de cohesión funcional, integridad, unidad, etc., -lo que le impone soportar y dominar algunas contradicciones epistemológicas-, sino en la noción de legitimidad. Ya no se puede hablar de una armonía orgánica ni de una cohesión sistémica a priori en el seno de las instituciones sino un trabajo simbólico por medio del cual adquieren una cierta coherencia discursiva (Berger y Luckmann, 2003).

La importancia aquí del concepto de legitimidad, sobre el que se abundará más adelante, es que reconoce una relación de 
poder, una oposición de fuerzas. A partir del resultado de esta, se establecen acciones y motivos plausibles o satisfactorios frente a otros no satisfactorios; algo que, cuando menos permite poner de relieve los elementos culturales, políticos, ideológicos, etc. que toman parte en dicha oposición de fuerzas en el intento de hacer prevalecer unas representaciones, unos esquemas de verdad o unos presupuestos ideológicos (con sus prácticas correspondientes) frente a otros.

Para el caso que se ocupa, el constructivismo induce a pensar la Educación Física escolar como una configuración contingente, incluso fortuita y casual -dentro, evidentemente, del marco de posibilidades que ofrecía el contexto en el que apareció-, fruto de condiciones, intenciones e intereses más o menos confluyentes de algunos grupos hegemónicos en torno a unas preocupaciones sociales nuevas. Pero tanto las nuevas preocupaciones como las soluciones se entienden no como ajustes sistémicos ni como optimización técnica, sino como producciones que toman cuerpo en el seno de pugnas simbólicas según un proceso en el que unos significados (y las consiguientes prácticas) adquieren respaldo -se tornan dominantes- y otros lo pierden.

En este sentido, la disciplina académica, más que dar continuidad a una "predisciplina" que habría estado presente en tiempos pretéritos, habría de entenderse como una realidad emergente -al igual tantos otros productos de la modernidad, en este caso un producto pedagógico-resultante de una confrontación de representaciones diferentes, a menudo en pugna y a veces en cierta sintonía - entre lo nuevo y lo viejo, entre lo culto y lo popular, entre lo religioso y lo profano, entre lo racional y lo tradicional, lo institucional y lo espontáneo, el saber y el hacer, etc.-, las cuales, sin sustancia ni proyecto definido -ni de antemano ni, en su transcurso- le fueron dando forma de disciplina académica como tal, de acuerdo con la capacidad de imposición de quienes en la liza social por afirmarse tenían la hegemonía. Por mejor decirlo, fueron construyéndola como materia escolar por acumulación, sustitución, sustracción, transformación, a menudo accidentales, casi siempre con un trasfondo político, económico, ideológico o de otra índole, en que las justificaciones funcionales -el trabajo simbólico por el que su supuesta practicidad fue obteniendo aceptación, adquiriendo legitimidad- se habrían ido elaborando incluso a posteriori de su configuración -o, a lo sumo, a la vez que dicha configuración-como una condición más de entre las que eventualmente fueron interviniendo en su génesis.

Los casos de la inclusión del deporte en las Publics School inglesas de mediados del siglo XIX o de la gimnasia filantrópica en las escuelas del norte y centroeuropa por la misma época son paradigmáticos: ponen de relieve la escasa importancia que en un principio se concedió a unas y otras prácticas en sus respectivos entornos como tales actividades educativas $\mathrm{y}$, sin embargo, una vez instaladas, el discurso pedagógico encontró solícitamente las justificaciones pertinentes para que las "conquistas" culturales de las élites fueran asumidas y naturalizadas por el sistema llevando a la escuela "materiales" de su propiedad. Otro ejemplo paradigmático es el que tiene que ver con la introducción del juego, algo más tarde, en la Educación Física: casi ningún discurso sobre la materia prescindiría hoy del juego, e, incluso, la mayoría lo calificarían como uno de los más importantes, propios y genuinos contenidos, un "universal" aduciendo para ello toda clase de teorías biológicas, psicológicas, antropológicas, etc. Sin embargo, su producción como ingrediente de la educación occidental dista mucho de lo que podría considerarse una solución técnica de índole didáctica producto de sesudos razonamientos pedagógicos. La inclusión de la actividad lúdica en la escuela y en la Educación Física tiene más que ver con la redistribución del tiempo académico, cuando este empezó a ocupar jornadas casi tan prolongadas como las de la fábrica: como mecanismo de descompresión diversiva y como medida profiláctica ante el tedio 
y el hacinamiento de unos establecimientos escolares, cuya función más importante era dar cobijo físico y mantener bajo vigilancia a los hijos desatendidos de los obreros. En este sentido, la discusión sobre la idoneidad de la actividad lúdica tuvo más que ver con las diferencias ideológicas en torno al uso del tiempo escolar para la formación del proletariado que con cualquiera otra razón didáctica; finalmente, su introducción fue el resultado de una pugna simbólica -larga y compleja- en la que cada clase social en liza habría tratado de imponer su propio modelo de acuerdo con sus respectivas expectativas en la que el proletariado tenía escasa capacidad para imponer su sensibilidad. No cabe duda de que a la clase obrera del siglo XIX le interesaba más bien poco que sus hijos jugaran en la escuela (aprendieran jugando, jugaran para aprender, aprendieran como si jugaran o jugaran a que aprendían algo); les interesaba principalmente que estuvieran a cubierto y que aprendieran los rudimentos intelectuales y de hábito más elementales. Sería la burguesía acomodada y parte de clase ociosa, con una idea muy diferente de la infancia -especialmente la referida a sus propios hijos-, con unas expectativas también distintas para ellos y con patrones de gusto más elaborados, los que propiciarían, no sin conflictos, la lenta incorporación de actividades no prácticas en la escuela y, eventualmente, la sistematización de estas como materia educativa y en particular de la Educación Física.

$\mathrm{Si}$ las nociones del constructivismo son válidas para el análisis del proceso de conformación de los contenidos y de la propia idea de la Educación Física, no son menos válidas en lo que respecta a la definición del elemento primario sobre el que la Educación Física interviene, esto es, el cuerpo. En realidad, la noción de cuerpo y la filosofía subyacente a las ideas de cuerpo "educado", cuerpo "instruido", cuerpo "formado" (o "bien formado") constituyen el basamento más firme sobre el que opera históricamente la evolución de la materia escolar; pues bien, esa noción y esa filosofía subyacente son lo suficientemente inconstantes y veleidosas como para que se pueda atisbar casi de un golpe de vista lo insustancial de la disciplina en el curso de la historia.

Ahora bien, que del constructivismo puedan extraerse interpretaciones de corte más acomodaticio orientadas a justificar el discurso técnico vigente, o de corte más crítico, orientadas a una revisión profunda de los fundamentos de dicho discurso, no socava o, al menos, no debería socavar los principios epistemológicos en los que se fundamentan sus planteamientos. A este respecto, es perfectamente compatible con el constructivismo la justificación de dicho discurso técnico bajo la premisa, por ejemplo, de que la modernidad decimonónica impuso nuevos hábitos, nuevas necesidades de capacidad y eficacia física que hicieron necesaria la aparición de la Educación Física escolar y sus contenidos para satisfacerlas. Valga como ejemplo de esta consideración, que se podría denominar como constructivismo débil: el sempiterno argumento, aún presente en los idearios de la formación de profesores de Educación Física, de que los niños y las niñas cada vez están menos tiempo en la calle y hacen menos actividad física como justificación de la materia académica en el currículo escolar. Desde la perspectiva de este artículo, en todo caso, se hace eco de una concepción menos neutra y también menos instrumental de las configuraciones sociales y del propio currículum. Se adscribe a la idea de que la Educación Física escolar aparece de la mano de las nuevas políticas (más o menos coercitivas) que sobre la individualidad y su gestión se pusieron en marcha desde finales del siglo XVIII en Europa occidental y cuyos vértices principales se podrían resumir en tres: en primer lugar, la aparición de la escuela como institución de acogida de la infancia fundamentalmente masiva, asistencial -cuando no vigilante o coercitiva-, adoctrinadora, normalizadora y reguladora del comportamiento infantil por encima del carácter instructor que con el tiempo iría desarrollando; en segundo 
lugar, el desarrollo de la propia noción de infancia como una clase específica de sujetos cuya característica más definitoria era la incapacidad social transitoria, por lo que cuajó la idea de someterla a un proceso largo de inoculación de civilidad institucional; y, en tercer lugar, el desarrollo de la ciencia moderna: por una parte, la secularización y desarrollo de la ciencias de la naturaleza - con la medicina a la cabeza- dispuestas a ofrecer una visión racional y experimental del humano, más allá de las artes curativas del cuerpo y, por otra, la emergencia -aún tímida pero ya sin retorno- de las Ciencias Sociales y en especial de la Pedagogía y la Psicología del desarrollo como disciplinas que operarían a favor de la individualización del sujeto y en gran medida en su normalización por medio de una mirada a menudo subsidiada por los saberes positivos y, desde luego, al servicio del orden social y moral imperante.

La hipótesis que a este respecto se plantea es que la Educación Física constituye, antes que nada, un dispositivo administrativo del buen gobierno corporal; es decir, el resultado más organizativo que pedagógico de nuevas preocupaciones respecto del sujeto y la gestión de la subjetividad en el seno de una sociedad dominada ya por la moralidad burguesa en la que el cuerpo, que siempre se había mantenido en un difícil equilibrio cultural, empezaba a cobrar protagonismo, no sin traumas ideológicos, en la definición de la identidad. En este sentido, antes que un mero desarrollo de las soluciones técnicas de siempre a las necesidades de aprendizaje corporal (postura sustancialista) y antes que una solución técnica novedosa a problemas nuevos (postura constructivista débil), se plantea la emergencia de la Educación Física como la creación de una forma político-administrativa difusa de entre las muchas que puso en práctica la modernidad como mecanismo de ordenación y control social. Más concretamente, como mecanismo que, siendo inicialmente un conjunto de estrategias diversas y dispersas destinadas a limitar los extravíos del régimen normalizado de la virtud de la recién creada infancia, fue encontrando cabida en los establecimientos escolares donde se fueron amalgamando contenidos, métodos e idearios para ir dando forma con el tiempo, y no sin conflictos de orden pedagógico, a una nueva materia escolar.

En cualquier caso, ya sea bajo una perspectiva más débil o más fuerte del constructivismo, los planteamientos de Elias (1978, 1989, 1990) sugieren, cuando menos, la existencia de un comienzo que, por difuso que este sea, ha de poder ser identificable tanto en las fechas como en los acontecimientos que lo impulsaron. Sugieren que en dicho comienzo no debió existir ningún "proyecto pedagógico" en el que la materia apareciera siquiera esbozada como disciplina escolar, que debieron cruzarse ideas y creencias diversas, intereses contrapuestos, concepciones diferentes de hombre, de cuerpo, de sociedad, de escuela, etc., las cuales debieron entrar en pugna -tal vez más coyunturales que sobre el fondo de lo que debería ser o no la Educación Físicapero que, en su conjunto, irían dando lugar a una práctica escolar nueva, a unos discursos nuevos, a una concepción del espacio y del tiempo institucional nueva. En definitiva, esto se da para producir una disciplina escolar nueva que, no obstante, habría de seguir un largo peregrinaje y sufrir intensas transformaciones para subsistir tanto siendo tal vez otra cosa diferente a que lo que empezó siendo, así como cumpliendo otros fines que aquellos que inspiraron a sus mentores y, por lo tanto, así justificándose por otras funciones que por las que cumplía o decía cumplir en sus comienzos. A este respecto, la gran variabilidad de significados que han tenido las operaciones sobre el cuerpo para los agentes académicos involucrados en la consolidación de la Educación Física, refuerza el argumento que se trae a colación: la Educación Física escolar es el resultado de algo más que la mera evolución técnica de una misma sustancia. Esta podría ser la expresión de construcciones teóricas muy 
diversas a propósito de prácticas, intenciones y proyectos también diferentes que a las cuales solo cierta representación historicista les ha dado el sentido unitario, lineal y finalista al que se refería más arriba.

Aquí, la importancia de las observaciones de Elias $(1989,1990)$ reside en que ayudan a fijar el punto de mira de manera más precisa en el sentido de que sugieren la posibilidad de descartar asuntos que, aunque la historiografía evolucionista al uso ha unido, tienen poco que ver entre sí e, incluso, se abre la puerta a incorporar a la explicación histórica asuntos que no fueron tenidos en cuenta al pasar por demasiado ajenos a lo que sucedía en las aulas con los cuerpos de los escolares: los ya mencionados dispositivos de control de la población por medio de la gestión de la subjetividad, pero también otros dispositivos ideológicos encaminados a consolidar una idea del mundo y de la sociedad (la definición y puesta en práctica de las nociones de niño, desarrollo infantil, aptitud, mérito, experiencia de sí, autorrealización y con ellas las nociones de cultura, sociedad, individuo, hombre, mujer, etc.). A este respecto, cabe mencionar aquí lo que Foucault denominó la apropiación social de discursos: "todo sistema de educación [señala] es una forma política de mantener o de modificar la adecuación de los discursos, con los saberes y los poderes que éstos implican" (1999, p. 45).

Sin embargo, el análisis constructivista no sólo descarta la concepción finalista del desarrollo de la materia, sino también la antihistórica postura de la aparición por azar; a este respecto, los términos de "fortuita" y "casual" que se empleaban más arriba como condiciones de su configuración hay que tomarlos en sentido relativo: fortuita y casual en el marco de las posibilidades que ofrecía el panorama cultural, social y político en un momento de transformaciones institucionales profundas y también transformaciones del comportamiento $\mathrm{y}$ de la sensibilidad. Los proyectos de salubridad de los establecimientos escolares, programas de contención del vagabundeo infantil, planes de formación de la mano de obra para fábricas o de los soldados para los ejércitos, etc. pudieron hacer más por la categorización de los aprendizajes corporales como disciplina académica que toda la tradición erudita sobre los beneficios pedagógicos del ejercicio físico en la que se ha pretendido hallar prefigurada la educación física escolar. Cabe apelar de nuevo al análisis foucaultiano en relación a la mutación general que se opera en las formas de administración disciplinaria de la época (Foucault, 1979): para el caso tratado se diría que pequeñas transformaciones, leves reformas, invenciones, inclusiones, exclusiones, etc., remedios todos que fueron siendo aplicados a la hora de controlar-ejercitar el cuerpo en los establecimientos escolares, para responder a necesidades superficiales de coyuntura, terminarían construyendo un nuevo y peculiar mecanismo escolar (pedagógico) para disciplinar, uniformar, a la vez que para distinguir. En este sentido, cada una de las pequeñas disposiciones encaminadas a resolver problemas de orden, de disciplina, de eficacia distributiva de los alumnos, de control y supervisión de la higiene, de optimización de selección de los más aptos para tales o cuales tareas, de perfeccionamiento de los sistemas de detección y segregación de los sujetos "insanos" o "insociables" etc., cada una de las cuales por sí mismas intrascendentes, apenas perceptibles, catapultaron en su conjunto un proceso de mutación general del sistema educativo y de la escuela en particular en el emergente arte de gobernar el cuerpo. Arte en el que la Educación Física es sólo un apéndice menor, aunque muy visible, de la dominación cultural del cuerpo.

Valga señalar, a modo de conclusión de este apartado, que lo que aquí se discute, más allá del modelo interpretativo de la historia de la Educación Física, es el grado de pertinencia pedagógica que cabe otorgar a la disciplina cuya institucionalidad se justifica, en una buena parte, en la necesidad de intervenir en el desarrollo y aprendizajes del cuerpo de acuerdo con una modalidad 
comprensiva del proceso educativo en la que los mejores avales descansan en la historia contada. Si se resolviera que dicha historia contada ha ocultado o escamoteado, por acción u omisión, ciertas dimensiones de la acción pedagógica (como la política, la ideológica, etc.), entonces se hace necesario una profunda revisión de la genealogía que, en todo caso, permita debatir acerca de las funciones sociales que pueda cumplir -las explícitas y las latentes, las declaradas y las ocultas-y que, asimismo, admita discutir a propósito de las posibles (y las imposibles) concepciones pedagógicas (reproductivas, reformadoras, clasistas, igualitaristas, emancipadoras...) que esta haya podido tener antes y pueda suscitar en adelante.

\section{Legitimación del discurso técnico y sus producciones}

\subsection{Dominación simbólica vs. funcionalidad práctica}

Se señalaba más arriba que, entre otras características, el análisis constructivista hace descansar el significado y la pervivencia de las instituciones no en una armonía orgánica o sistémica, no en una funcionalidad práctica supuestamente inherente a la estructura de la realidad en la que se encuentran, sino en la legitimidad que estas adquieren como resultado de un trabajo simbólico. Es decir, como resultado de distintas operaciones de significación que son las que les confieren coherencia (explicación y justificación) dentro de un cierto esquema de representaciones; desde luego, en el interior de las representaciones dominantes o, en terminología foucaultiana, de los esquemas de verdad. Abundando en la cuestión, y haciendo eco para ello de la terminología de Berger y Luckmann (2003), se puede decir que la lectura constructivista fija la atención en los procesos sociales por medio de los cuales las instituciones llegan a ser objetivamente disponibles y subjetivamente plausibles en el seno de un determinado universo simbólico. En todo caso, el concepto de legitimidad remite a la idea de apropiación que empleara Elias (1989) para referirse a los modos en que tiene lugar el proceso de la civilización de las costumbres y, por extensión, el proceso mediante el que se configuran las relaciones interindividuales: desde el comportamiento mesurado a la mesa -con el consiguiente manejo de instrumentos como cucharas, tenedores, servilletas, etc. y la muestra de una cierta regularidad del gesto o distinción en el gusto-, hasta la adopción de una determinada postura "higiénica" o "saludable" en el pupitre o en el lecho, pasando por la continencia emotiva y corporal del sujeto en las relaciones con los demás o consigo mismo, nada de lo cual es absolutamente natural o producto de un escrúpulo natural (Elias, 1989). No son, apunta, producciones técnicas que hayan surgido con un objetivo funcional o práctico claramente reconocible, sino que van consolidando poco a poco su forma, delimitando su función muy lentamente -incluso a lo largo de siglos-, regularizándose su uso por medio de las distintas capas sociales mediante un mecanismo de apropiación de abajo arriba o de arriba abajo, no sin tensiones culturales y sociales, en el que las significaciones se van modificando de acuerdo con los rasgos predominantes del círculo social en el que se instalan. Lo significativo del planteamiento de Elias (1989) es la perspicacia interpretativa del proceso civilizatorio en términos de configuración social, en el sentido de que permite comprender cómo la aparición y consolidación de cualquier comportamiento en el curso de la civilización suele obedecer antes que a una solución técnica razonada ante un problema práctico dado, a una pugna simbólica de tendencias contrapuestas de identificación-diferenciación social mediante la adopción (por invención o por apropiación) de expresiones físicas, ideas y sentimientos inéditos o raros, delicados, exquisitos, etc. $\mathrm{y}$, asimismo, a la incorporación de pautas de relación y trato paulatinamente más 
complejas, elaboradas y autocontroladas. En cualquier caso, todo esto mediante la adopción de expresiones inicialmente exclusivas (y excluyentes) que otorgaban a quienes las exhibían un cierto carácter distinguido frente a lo común, lo vulgar, lo simple e impulsivo. Muchas de estas expresiones, con el tiempo, desaparecerían y otras se difundirían obteniendo carta de naturaleza y legitimidad.

La conformación de las instituciones sociales en tanto que mecanismos de regulación, tipificación, habituación o de administración del comportamiento en diferentes órdenes y campos, no sólo no escapa a este análisis sino que incluso resulta paradigmática por cuanto las reglas por las que se rigen los miembros que integran dichas instituciones obedecen a la misma lógica de interacciones e interdependencias: el trabajo o la lucha simbólica por la legitimidad. Más aún, es en el proceso de conformación histórica de las instituciones (la sexualidad, el tiempo, la ciencia, la familia, el deporte, la educación, el derecho, la lengua, el dinero, etc.), que el racionalismo presenta como exteriores y trascendentes a los individuos, en el cual según los planteamientos constructivistas se configura la identidad (individual, colectiva, infantil, femenina, masculina, proletaria, burguesa, corporal, étnica, etc.) en tanto que incorporación -no electiva y en gran parte inconsciente- del habitus dominante del grupo de pertenencia.

Bajo esta perspectiva, la consideración del carácter funcional que explícitamente expresa el discurso técnico de la Educación Física escolar -donde las justificaciones (utilitarias) aparecen como avales de su pertinencia institucional- se revela, cuando menos, problemático. En efecto, el cometido que dicho discurso atribuye a la materia como condición necesaria y garante del desarrollo de cualidades físicas o de competencias y habilidades en los distintos ámbitos del comportamiento del sujeto -físico, social, emocional, intelectivo, moral, etc.- pierde el más importante de sus sustentos epistemológicos por cuanto las propias nociones de cualidad o capacidad física, competencia, habilidad, incluso desarrollo infantil e infancia, etc. junto con todas las que modernamente han engrosado el vocabulario pedagógico de la Educación Física (autonomía, autoconocimiento, autosuperación, autorrealización, salud, etc.) se muestran relativas y contingentes, tan solo válidas en el interior de esquemas de verdad dominantes y de acuerdo con los desiderata prácticos de los grupos hegemónicos. Dejan de aglutinar esa clase de sustancia indiscutible de la categoría "educar el cuerpo" para revelarse como categorías fuertemente convencionales aunque, eso sí, prevalentes, puesto que de hecho han logrado conferirle legitimidad curricular y social mediante una dinámica interna de creación de conocimiento tecnológicamente explotable. Para ello, una buena parte de los esfuerzos discursivos han debido ocuparse en ocultar el carácter convencional de dichas categorías dotándolas, mediante la aplicación sistemática del saber positivo y de la razón instrumental, de una apariencia de practicidad -al servicio de la funcionalidad orgánica- que permite a las estructuras de poder consolidarse en virtud de su carácter "natural". A este respecto, en la medida en que el proceso de legitimación se ha asentado en un trabajo simbólico que ha hecho concebir el cuerpo, su forma, sus operaciones, sus funciones, sus necesidades, etc. como naturales, explicadas y explicables mediante las técnicas de conocimiento típicamente experimentales, se puede decir que se trata de un proceso de legitimación por naturalización.

Resulta clarificador lo que Mills (1999), a propósito de la filosofía moral del utilitarismo y los modos de legitimación del poder, calificaba como practicidad liberal; justamente se refería a esa clase de concepción de la utilidad cuya metafísica "orgánica" o "natural" -como la que parece legitimar a la Educación Física- subraya todo lo que tiende al equilibrio armonioso y donde los cambios o no se advierten o se toman como meros síntomas de lo "patológico" o "inadaptado", es decir, como una desviación de la naturaleza que es preciso 
corregir y en cuyo auxilio acude la técnica. Mills (1999) incide en el carácter conservador de la practicidad liberal, la cual, frente a la practicidad antiliberal, controladora, disciplinaria y orientada al lucro industrial, resulta simpática a aquellas personas que por su posición social y en virtud de algún grado de autoridad, manejan casos individuales (jueces, trabajadores sociales, higienistas mentales, maestros, etc.), en los cuales se tiende a pensar de acuerdo con las "situaciones" concretas, a resolver problemas prácticos siguiendo los patrones existentes, lejos de cualquier controversia ideológica y de cualquier intento de interpretar y, mucho menos, de transformar el conjunto. Evidentemente, puesto que descubrir problemas prácticos y enunciarlos es hacer valoraciones, la practicidad liberal no es ajena a la moral ni es apolítica; se configura como una sociología moralizadora en la que se toma como problema aquello que se aparta de lo común, lo que no se ajusta a los principios de orden y estabilidad; es especialmente moralizadora cuando dichos problemas se enuncian en relación con las instituciones respecto de las que se supone necesitan mayores dosis de racionalidad (científica o tecnológica) sobre principios del tipo logro de la estabilidad y el orden, el progreso social, la adaptación, la integración, etc. -como por ejemplo la escuela, la medicina, la cultura- que con frecuencia constituyen, señala Mills, una propaganda a favor de la conformidad con las normas y rasgos idealmente asociados con la clase media de la pequeña ciudad.

Tal vez se puedan extraer de esto algunas consideraciones sugerentes para interpretar la Educación Física escolar en tanto que institución sustentada en un alto grado por el discurso didáctico, cuya practicidad liberal (racional, funcional y sistémica) termina por otorgarle carta de naturaleza "natural", categoría de dato empírico-legitimidad científica- lejos de toda discusión sobre los elementos ideológicos, políticos e, incluso, morales que median en la acción pedagógica del cuerpo.
No se puede evitar señalar que todo discurso que interpreta y concibe las "cosas del mundo" las ordena y las clasifica de un modo contingente, casi siempre con verosimilitud lógica y, a menudo, con suficiente fuerza persuasiva como para hacer de sí un modelo de percepción, una estructura de significaciones, de valoraciones y de acción; es decir, con capacidad para construir el "mundo de las cosas". Pues bien, bajo una bien elaborada argumentación lógica y clasificatoria, el discurso pedagógico de la Educación Física -y las consabidas prácticas en las que se sustenta- no es ajeno a esta condición de constructo o convención estructurante, como lo es, por otra parte, cualquier discurso sobre cualquier materia escolar en su respectivo ámbito de representaciones. En el caso que se está analizando, se configura como un constructo estructurante de la corporeidad pedagógica o, si se prefiere, del sujeto corporalmente educable, para lo cual aplica los parámetros de sistematicidad, calificabilidad, homogeneidad, etc. que imponen los modelos tecnocráticos propios de la institución escolar. Pero dicho discurso, en la medida en que construye el cuerpo educable y legitima sus atributos (el cuerpo hábil, eficaz, sano, diligente, aseado, atento, obediente, experimentado, etc.), en cuanto hace visibles y "verdaderas" ciertas condiciones de ser cuerpo -finalmente reductibles a una división binaria superficialmente técnica (cualificado/no cualificado)-, no solo resiste la prueba de las argumentaciones sino que a menudo puede resistir la prueba de los hechos; y es que el mundo de las representaciones no es sólo un mundo de imágenes, es el mundo que las personas construyen y que aceptan, es "el mundo"1. Se diría entonces que la Educación Física escolar no aparece finalmente como una modalidad interpretativa de entre diversas posibilidades de entender la educabilidad del cuerpo: en tanto ha sido configurado cierto modelo de este y cierto modelo educativo como instituciones pedagógica y socialmente válidas, las cuales han producido ya una realidad incuestionable -0 muy difícil de cuestionar-, han elaborado el 
universo posible (y el no posible) del cuerpo como objeto de intervención educativa. Han trazado los límites reconocibles de la Educación Física escolar, que son aquellos que la autoridad pericial no permitiría traspasar, so pretexto de mantener la "esencia" de la materia. Algo que refuerza de tal manera la tradición profesional y el discurso pedagógico oficial que no solo hacen imposible el cambio sino que, como se señalaba al comienzo, cualquier crítica que vaya más allá de la mera alternativa de contenidos o de métodos sea tachada de irracional o de extravagante.

Pues bien, siendo la categoría "educar el cuerpo" una entidad fuertemente convencional, aunque legítima, dicho universo posible -la institución del cuerpo como objeto escolarmente educable- debe soportar, según se apuntaba en el apartado anterior, algunas contradicciones para contener y dominar su sentido dentro del marco funcionalista-sustancialista en el que obtiene su reconocimiento. En otras palabras, debe lograr que los significados por los que dicha institución es reconocida como agente social útil o funcional en el ámbito en el que dice serlo (el desarrollo necesario de habilidades y capacidades corporales de los sujetos) mantengan su credibilidad, a pesar de aquellas argumentaciones, teorías, evidencias, pruebas, etc. que los pongan en tela de juicio o que, simplemente, revelen el carácter relativo, incluso arbitrario, de las categorías pedagógicas y sociales en las que se apoya. Ahí, a la insidiosa verosimilitud argumental del discurso técnico, cuya tenaz relación entre medios y fines parece inexpugnable, se une la acomodaticia ambigüedad de los sucesivos discursos pedagógicos institucionales del cuerpo pergeñando un aparato de creencias, a menudo dogmático -los mencionados tópicos discursivos-, bien adaptado a los saberes dominantes (sobre todo de la biología y la psicología del desarrollo), bien adaptado a la tradición positivista y de fácil sedimentación en el sentido común; al menos, de fácil sedimentación en el sentido común de los enseñantes de la Educación Física.
Si en las líneas que siguen es posible descubrir y describir suficientemente estas contradicciones, si se pueden de señalar algunas de las creencias que, a este respecto, se configuran al calor del discurso técnico dominante, se estará poniendo de relieve que el discurso de la funcionalidad práctica de las intervenciones físico-educativas escolares (el discurso oficial que legitima la Educación Física escolar) es sólo una coartada discursiva que otorga aceptabilidad social a lo que no es sino el resultado de luchas simbólicas por imponer una forma de hacer y de entender el cuerpo, así como la forma de entender las relaciones (las propias y las de los demás) con él. Se trata, en todo caso, llegado a este punto, de poner de relieve en qué consiste dicha forma de impositiva de hacer y de entender el cuerpo, en qué consiste el trabajo de simbólico por imponer una determinada forma de entender las relaciones con los cuerpos y qué consecuencias tiene.

\subsection{De la capitalización de propiedades formativas y la desubjetivación del cuerpo}

Talvez la más elemental contradicción quela Educación Física escolar ha de soportar para contener su significado en el marco funcionalista es la que tiene que ver con la corporalidad que dice producir y la que, de hecho, produce. De acuerdo con el carácter contingente y convencional de la disciplina académica, antes que enseñar al cuerpo, la acción primera de su propia legitimación ha sido necesariamente la construcción del cuerpo apto para ser enseñado; es decir, escolarmente enseñado. Ha debido configurar, si quiera esquemáticamente, las condiciones en las que el cuerpo puede y debe ser enseñado dentro de la escuela; ha debido perfilar los límites del universo posible de la intervención pedagógica sobre el cuerpo así como una batería de justificaciones plausibles. Pues bien; a tenor de las cosas que se le enseñan, cómo se le enseñan y cómo se han ido estableciendo tales 
enseñanzas a lo largo de su breve historia, parece que dicho universo pedagógico ha sido elaborado no tanto bajo la premisa de qué es lo que conviene aprender al cuerpo, a los cuerpos, y para qué, como por la necesidad de encontrar un lenguaje adaptado a lo que ya se enseñaba; un lenguaje técnico que autorizara y acreditara el tratamiento institucional del cuerpo sin levantar sospechas de llevar a cabo un ejercicio coercitivo, de dominación cultural o de inconfesable moralización; es decir, donde la elaboración de las justificaciones a propósito de lo ya dado, de lo "esencial", han prevalecido sobre los intentos de transformar y adaptar lo establecido a las nuevas expectativas sociales.

A este respecto, antes que explorar las necesidades de los cuerpos individuales, los cuerpos-sujeto, ha elaborado un discurso polivalente y ambiguo, un discurso acomodaticio, que, en el momento actual, superadas las funciones diversivas $y$ descompresoras que siempre cautivaron a los promotores y adalides de la Educación Física, se sostiene bajo la ilusión pedagógica de la transferencia de las competencias físicas, la ganancia de eficacia o de salud que tanto seduce a la racionalidad instrumental. Aquí cabe distinguir dos tópicos. El primero consiste en la formulación de una cada vez más abigarrada mezcla de propiedades formativas y reformativas en la que acaba encontrando acomodo todo género de utilidades, atributos y objetivos de acuerdo con los discursos imperantes; se comentará este tópico con la denominación de capitalización intensiva de propiedades. El segundo de los tópicos, tiene que ver con la consideración del cuerpo como un objeto natural y neutro, vacío de contenido, donde la Educación Física vendría a llenarlo de capacidades, habilidades, aptitudes, etc. -también consideradas naturales y neutrasmediante un diseño didáctico pericial que toma como referencia las leyes del desarrollo evolutivo, sobre todo biológico y psicológico, del niño; es decir, mediante un diseño tecnológico que encuentra acomodo en la concepción sustancial de la infancia y que a, la postre, relega a la mínima expresión los condicionantes sociales de la desigualdad tales como la clase social, el capital cultural y económico o reduce las diferencias de género a caracteres sexuales; se aplica a este tópico la expresión de desubjetivación del cuerpo por cuanto tiene de sustracción de la subjetividad social del cuerpo en aras de una homogeneidad pedagógica que parece encontrar en la permanencia sustancial de la anatomía.

\subsubsection{Capitalización intensiva de propiedades}

En cuanto al primero de ellos, como para apuntalar un endeble edificio discursivo que no es capaz de sostener la materia académica sobre el inconfesable cometido de transmitir una parte del capital cultural hegemónico del cuerpo mediante la inculcación de ciertas habilidades físicas y el autodominio corporal, se ha debido desarrollar todo un andamiaje teórico por el que, bajo los ambiguos emblemas de la "formación del carácter", la "educación integral", la "socialización", la reactivada "educación física para la salud", u otros eslóganes similares, que le ha permitido mostrarse socialmente como una institución más plausible. Así, junto a las destrezas corporales propiamente dichas -del tipo y condición que en cada contexto y momento político hayan sidotodas las formulaciones institucionales de la materia han invocado a alguna clase inespecífica de valores tales como la autorrealización la autosuperación, el autoconocimiento, etc., que, unidos a las también inespecíficas aptitudes sociales, afectivas o cognitivas, han permitido salvaguardar la continuidad de los modelos dominantes y, sobre todo, han protegido a la Educación Física de la crítica ante lo que podría ser visto como una dilapidación del tiempo escolar. Pero esta capitalización intensiva de propiedades no parece sino un mero engrosamiento retórico, cuyos orígenes se remontan a los mismos inicios de la materia, que parece encaminado a ocultar la deriva y la 
inoperancia pedagógica de las técnicas, las habilidades y las capacidades en las que instruye y, por añadidura, a ocultar el carácter impositivo y arbitrario del material ideológico, emocional y práctico del cuerpo que dichas técnicas, habilidades y capacidades llevan implícitas en la propia realización. Demasiados objetivos y, sobre todo, demasiado ambiguos, demasiado dispersos y trascendentes, al tener en cuenta la escasa relevancia y significación que tiene con relación a todo ello superar o no los test de capacidad física que en tantas escuelas e institutos se imponen como condición para superar la asignatura; el resultado no es otro que la homogeneización cierta de la representación y uso cultural del cuerpo. Esto se aprecia, muy especialmente, al considerar la escasa relevancia que tienen dichas pruebas y, en general, los contenidos en los que se apoyan, los cuales responden a una elaboración selectiva de prácticas corporales escasamente representativa de los intereses y expectativas (en relación con las perspectivas clase social, de género, o de cultura) de un alumnado cada vez más diverso. No se puede olvidar con relación a esto que la escuela, si bien es un lugar al que van todos, en absoluto ha sido construida por todos, no es de todos ni, por definición, responde a las necesidades de todos.

Se podría decir, a este respecto, que el discurso de la Educación Física se ha preocupado más por establecer lazos de unión entre la escueta instrucción que tradicionalmente ha impartido y un ambicioso ideario formativo antes que dotar a la materia de elementos instructivos cuya significación cultural y social fuera verdaderamente relevante para los escolares, fueran cuales fueren sus condiciones, intereses, necesidades y expectativas con respecto a los usos del cuerpo y, sobre todo, teniendo en cuenta precisamente la gran diversidad de condición de estos. En ese sentido, aunque ya esté prácticamente desterrada la imagen del profesor de Educación Física colgado de un silbato, un cronómetro y un cuaderno de notas, pasando formularios de capacidad (antes, durante y después de sus enseñanzas), ilustra muy bien una parte de la historia de la materia y de los referentes que aún siguen informando sus prácticas: la combinatoria del control infinitesimal de tiempo y la organización de la actividad colectiva en aras de una experiencia corporal que sigue siendo la retórica pedagógica que legitima la ética y la estética de la eficiencia, la obediencia y del orden medidos por medio del logro deportivo o similar, en los que la fácil trasgresión del grito, la risa, la escapada circunstancial o el escaqueo permiten mantener el espejismo de la Educación Física como materia que rompe la continuidad coercitiva de la institución escolar. Sin embargo, bajo la ilusión de la explosión libertaria del cuerpo que se mueve, la Educación Física se muestra como un espacio de visibilidad absoluta del sujeto, un espacio de constante tutelaje -especialmente ideológico-justamente porque, a diferencia de otros espacios académicos donde el cuerpo no importa,enellaelcuerpoeslopermanentemente visible, lo permanentemente actuado, lo continuamente regulado, lo constantemente objetivado. Si en la Educación Física estar es estar corporalmente actuando, si pensar es moverse, si la conciencia es pararse y sentir, etc. no cabe duda de que el ejercicio físico, adopte la modalidad que adopte, se configura como una prosaica ceremonia de confesión en la que es preciso moverse, moverse ante los demás y moverse bien: exhibición ostentosa de los más diestros, los mejor dotados, los más virtuosos cumplidores del régimen, pero también vergonzante muestra del desmañado, el flojo, el remolón, el torpe, el gordo y sobre tantos otros que como ellos sufren, en gran medida, la desposesión de su propio cuerpo.

\subsubsection{Desubjetivación del cuerpo}

El segundo de los tópicos en torno a la corporalidad que produce la Educación Física condice estrechamente con la concepción sustancialista de la realidad a propósito de la cual se habló en el apartado número dos. Referido al cuerpo el sustancialismo 
consiste en la consideración de este como una entidad meramente biológica y mecánica enclavada en una sociedad, antes que una realidad social propiamente dicha. Una entidad cuyos atributos -objetivables mediante variables orgánicas y mecánicas, incluso, psicológicas- permitirían tratarlo como "cosa" genérica, como algo dado por la naturaleza; así sería la Educación Física siempre, y se diría que únicamente, el conjunto de actuaciones encargadas de producir en ese cuerpo "natural" las condiciones necesarias para su desenvolvimiento y su adaptación en y a cada contexto. Un conjunto de actuaciones para su "puesta a punto" dando por buenos, también, muchos de los elementos de la vieja concepción mecanicista del cuerpo fundada sobre los principios del racionalismo cartesiano.

Eso es lo que se definiría como la desubjetivación del cuerpo en el sentido de que la hipertrofia discursiva de lo orgánico, es decir, de los atributos objetivables mediante las leyes de la biología y disciplinas afines, termina por invisibilizar los rasgos subjetivos de la corporalidad. Reduce la pluralidad social de los cuerpos al cuerpo unitario y genérico; desconfigura las corporalidades para reconfigurarlas sintéticamente en el cuerpo abstracto, el cuerpo "resumen" que tan bien representa el atlas anatómico que frecuentemente preside las paredes del gimnasio escolar o los murales del departamento de Educación Física.

Como la Educación Física no puede y, tal vez, no está interesada en atender la diversidad que la subjetividad corporal impone tanto en términos de género, como de clase social, de etnia y en general de cultura, ha resuelto configurar el cuerpo escolarmente educable mediante la abstracción en los conceptos universales que la ciencia positiva proporciona; es decir, mediante la extirpación de los significados implícitos y explícitos de los rasgos corporales, mediante la desposesión de las necesidades y de las expectativas particulares o, lo que es lo mismo, mediante la homogeneización somática. La Educación
Física construye así el cuerpo sin historia, el cuerpo físico, del que importa, sobre todo, su adecuación a los discursos y a los recursos escolares: un cuerpo culturalmente abstracto, existencialmente vacío de contenido y políticamente disponible.

Culturalmente abstracto porque frente a la concreción identitaria que proporciona la experiencia y los aprendizajes corporales concretos en la discontinuidad-variabilidaddiversidad-conflictividad vital de lo cotidiano, se ve acuciado por la permanencia sustancial de la anatomía, por la regularidad del recurso didáctico, por la unicidad de las estructuras de aprendizaje institucional y por la conformidad a los esquemas hegemónicos de consumo corporal, lo que, sin embargo, disocia los aprendizajes del cuerpo de la vida cotidiana y sus requerimientos.

Existencialmente vacío de contenido porque la lógica de la escuela, a la que como se ha dicho van todos pero que de ninguna manera es de todos, exige como condición de aprendizaje gradual, sistemático, metódico y evaluable la disolución de todos y cada uno de los rasgos somáticos de inserción histórica. En cierto modo, el borrado de la memoria tanto personal como social y cultural del cuerpo permite la reordenación de las capacidades y habilidades esperables de acuerdo con los esquemas de representación y práctica instrumental de la agencia escolar. Dichas cualidades subvierten la diversidad en una pura diferencia de grado de cualificación que, por lo demás, exalta el rango a partir de la aptitud y, tal vez, de la actitud demostrada.

Y políticamente disponible, en fin, porque la experiencia corporal es siempre un espacio de producción ideológica; de este modo, una vez abstraídos los cuerpos en el concepto y despojados de su identidad más esencial, la política, queda apto también para la recibir la experiencia corporal posible en la Educación Física: la experiencia definida por el lenguaje y los esquemas de verdad escolares siempre en consonancia con los postulados éticos, estéticos, morales e ideológicos de la clase dominante: la 
burguesía próspera, culta, deportiva y saludable; mejor: la burguesía consumidora de prosperidad, cultura, deporte y salud.

La desubjetivación del cuerpo, la redefinición orgánica de este, es tributaria en gran medida de un proceso de medicalización ya viejo pero que en las últimas décadas ha hecho mella en prácticamente todas las esferas de la vida cotidiana de la cultura. La medicalización no sólo constituye un lenguaje para los asuntos del cuerpo sino, sobre todo, impone un estilo de vida y una concepción general del mundo que, entre otras servidumbres, supone una renuncia cada vez más importante a la libre decisión sobre el propio cuerpo en favor de una autoridad pericial. Esta ha derivado en una ordenación y normalización de la vida de los individuos que causan cada vez más presión, en las que el cuerpo empieza a ser, como le es propio al saber pericial, un espacio neutro y racional sobre el que se puede actuar, sí, pero donde las posibilidades de intervención sobre él, incluso las de índole didáctica, quedan estrictamente sometidas a las leyes de la Fisiología y de la Física (o disciplinas afines). Todo ello con el objeto de producir "mejoras" entendidas estas como requisitos del desarrollo, el perfeccionamiento la adaptación, el incremento de la eficiencia fisiológica o mecánica de cada sujeto.

El cuerpo se vuelve un espacio neutro y racional donde los conflictos que la indeterminación histórica de lo educativo provocan quedan resueltos ante la posibilidad cierta de la comparación de los cuerposorganismo y, por lo tanto, ante la reveladora definición del cuerpo plenamente educado: el "cuerpo eficiente", el "cuerpo hábil", el "cuerpo sano", el "cuerpo en forma", el "cuerpo en equilibrio psicofísico", etc., es decir, el cuerpo ajustado a los parámetros de la racionalidad positivista e instrumental en la que el diseño didáctico queda subsumido en un puro abastecimiento de "habilidades" y de "capacidades" físicas. En consecuencia, la evaluación de la acción pedagógica queda reducida a una mera valoración de dicha eficiencia mediante cualquier prueba estandarizada de capacidad, un acto evaluador cuya pretendida neutralidad valorativa solidifica la percepción funcionalista de la realidad y coadyuva a la perpetuación de los saberes hegemónicos y del orden social establecido. A este respecto, es revelador el principio en el que, a fin de cuentas, se materializa la filosofía evaluadora de la Educación Física escolar: la filosofía de la comparativa de cuerpos objeto: cuerpos suficiente, insuficiente o deficientemente "finalizados", cuerpos suficiente, insuficiente o deficientemente provistos del contenido motor esperable en términos de eficiencia, cuerpos bien o mal adaptados.

Es una filosofía comparativa en la que, en última instancia, las diferencias individuales (reducidas a capacidades, aptitudes, competencia, etc.) se computan, no como variables socioculturales (de recursos simbólicos, de intereses, de expectativas, de representaciones, de significados, etc.), sino como una variabilidad meramente técnica resultante de la ecuación entre el patrimonio biológico y aprovechamiento de unos medios técnicos (didácticos u otros) a disposición; medios que, por otra parte, son concebidos, construidos y aplicados a la consecución del ciudadano atleta, el ciudadano isotónico, el ciudadano disciplinado y eficiente, el ciudadano dispuesto y comprometido, como reza uno de los eslóganes más recurrentes en torno a los fines de la Educación Física, a mantener de por vida el hábito del ejercicio físico y a consagrarse a la búsqueda permanente del estado de salud.

\subsection{La ilusión didáctica: el conocimiento pericial como creencia}

$\mathrm{Ni}$ la concepción sustancial de la Educación Física - a partir de la cual, para muchos, su presencia en la institución escolar estaría justificada por sí misma-, ni la practicidad escudada tras una intensiva capitalización de propiedades formativas o bajo la consideración del sujeto pedagógico 
como una mera variable orgánica podrían constituirse como mecanismos legitimadores de la materia escolar si el conjunto de tópicos que les da forma no estuviera entretejido por la trama de creencias (pedagógicas) profesionales; si no estuviera sostenida por una genérica cultura profesional confiada, más allá de las críticas institucionales o del desánimo personal de muchos profesores, en la que suponen una (incontestable) virtualidad educativa de la experiencia corporal siempre que dicha experiencia esté sometida a una adecuada dirección pericial (didáctica). A esta clase de creencias y a ciertos dispositivos emocionales que operan en la configuración de la cultura profesional como inhibidores críticos es a lo que se denomina ilusión didáctica, de la que se analizan algunos aspectos en los siguientes subapartados. En el primero de ellos se aborda la cuestión del valor intrínseco de la materia vs. practicidad, en el que la hipótesis propuesta es que la invocación a dicho valor intrínseco es un subterfugio de legitimación ante la irrelevancia pedagógica de los contenidos, el cual tiene un sostenimiento que requiere, desde el punto de vista de este artículo, un sustitutivo pedagógico que solo puede proporcionarle la razón instrumental: la confianza en la validez del saber pericial (didáctico, psicopedagógico, etc.), uno de cuyos procedimientos, la generalización, la reducción de la realidad al concepto, funciona como mecanismo de prueba. En el segundo, se analizan algunos de los tópicos estrechamente relacionados con la actitud vocacional muchos de los profesores de Educación Física y con la secular vinculación de estos con uno de los contenidos más presentes e indiscutidos de la materia, el deporte: aquí se presenta con la denominación de la (supuesta) vastedad, suficiencia y neutralidad pedagógica del deporte por ser estos los mitos que tal vez más han impregnado la cultura profesional de la Educación Física. En el tercer subapartado, se aborda la creencia en la experiencia corporal y su virtualidad pedagógica como justificación de la materia que encubre la defensa de una modalidad cultural hegemónica de ejercitación del cuerpo.

\subsubsection{La practicidad en la Educación \\ Física: sobre la pesca de peces y otras especies pedagógicas raras}

Es bien conocido aquél viejo proverbio chino: "dame un pez y comeré un día, enséñame a pescar y comeré todos los días"; alegato pro-educativo donde los haya que, sin embargo, nada dice respecto de qué hacer si llegado el caso, todos los peces del río se extinguieran devorados por una escurridiza especie anfibia, por la voracidad piscícola de la creciente población china o si, por el cambio climático, el río chino desapareciera con todos sus nutritivos moradores: ¿seguirían los maestros chinos enseñando a sus alumnos a pescar? Bajo la perspectiva adoptada en este artículo, se diría que, si llegado ese caso, y para entonces el sistema educativo chino estuviera adaptado a los modelos pedagógicos occidentales -por ejemplo el modelo pedagógico de la Educación Física-, la respuesta sería: sí; en las escuelas chinas se seguiría enseñando a los escolares a pescar, y entre otros loables razonamientos que pugnarían por mantener tan poco prácticas enseñanzas dentro del currículo estaría aquél que dijera que lo importante del arte de la pesca no reside en la utilidad de esta para conseguir los frutos fluviales sino en el arte mismo, en la grandeza que entraña el dominio de sus aperos y en las capacidades que desarrollaría para, por ejemplo, cazar canguingos o chibiritainas ${ }^{2}$.

A este respecto, la ficción creada por Benjamin (citado por Peddiwell, 1939), a propósito de la educación paleolítica, constituye un contrapunto digno de tenerse en cuenta. Resulta en especial ilustrativa de los dispositivos de conservación curricular de la Educación Física escolar a pesar de las constantes innovaciones y renovaciones a la que se ve sometida, al menos teóricamente: había una vez peces, caballos lanosos y tigres dientes de sable, y así la educación 
incorporaba sabiamente captura-de-pecescon-las-manos, reunión-de-caballos-lanosos y ahuyentar-a-tigres-dientes-de-sable-confuego. Más tarde las aguas se enturbiaron y la captura de peces se hizo más difícil, los caballos fueron reemplazados por rápidos antílopes y los tigres por osos. Aunque la comunidad se fue adaptando a las nuevas condiciones para sobrevivir y hubo quien pidió cambios en el currículo, los sabios no oirían hablar de ninguna clase de cambio: con todos los intrincados detalles de la captura-de-peces, reunión-de-caballos y ahuyentamiento-de-tigres, el currículo escolar estaba ya demasiado cargado como para añadir las caprichosas novedades y ringorrangos que supondría aprender a confeccionar redes, a colocar trampas para antílopes o a matar osos; al fin y al cabo, dirían los sabios ancianos

no enseñamos a capturar peces con el fin de capturar peces; lo enseñamos para desarrollar una agilidad general que nunca se podrá obtener con una mera instrucción. No enseñamos a cazar caballos a garrotazos para cazar caballos; lo enseñamos para desarrollar una fuerza general en el aprendiz que nunca podrá obtener de una cosa tan prosaica como cazar antílopes con trampas. No enseñamos a asustar tigres con el fin de asustar tigres; lo enseñamos con el propósito de dar ese noble coraje que se aplica a todos los niveles de la vida y que nunca podría en una actividad tan básica como matar osos... Habéis de saber que la esencia de la verdadera educación es la intemporalidad, que hay verdades que permanecen a través de las condiciones cambiantes y que el curriculum de dientes de sable es una de ellas (Peddiwell, 1939, pp. 24-25).

Haciendo un esfuerzo de síntesis y recapitulando algunos de los aspectos ya tratados, se diría que existen dos grandes modelos de legitimación de la Educación Física en la práctica complementarios y a menudo con fronteras poco diáfanas pero que según su predominio caracterizan dos tipos de creencias en torno a la materia.

Uno de ellos, tal vez el primero en el tiempo, de carácter más pragmático, es el modelo de legitimación extrínseca, según el cual la Educación Física reportaría con el cumplimiento de sus objetivos pedagógicos beneficios en términos de habilidades, capacidades, disposiciones, aptitudes, actitudes, méritos, etc. que permitirían satisfacer algunas, o muchas de sus necesidades de orden somático: saltar, correr, resistir, meter muchos goles, cuidarse, etc. Otra cosa es quelas capacidades y habilidades en las que forme valgan o no al alumno, sean necesarias o no, estén ajustadas a las necesidades de todos, de unos pocos o de casi ninguno, sean discriminatorias por su concepción y selección o no, etc. (de lo cual ya se ha discursado). La cuestión que se dirime es que este modelo de legitimación parte de unas supuestas necesidades respecto de las que se proveen y sistematizan ciertos aprendizajes que permitan satisfacerlas con mejores garantías a quienes se someten al proceso educativo. Aquí, el diseño y el desarrollo curricular se puede definir como un proceso de búsqueda de las necesidades e intereses de los alumnos así como de los medios más eficaces para su consecución, eso sí, con toda la problemática que la definición, determinación y hallazgo de necesidades y medios supone. Esta es, sobre todo, el hallazgo de los principios en virtud de los cuales puede y debe hacerse la jerarquía de necesidades y, en función de ella, la selección de objetivos, de contenidos, de actividades o de métodos: por ejemplo, la definición de "alumno", la definición de "necesidades", la definición de "aptitud" o la definición de "sujeto (suficientemente) educado", etc.; esto es, la construcción del proyecto educativo que toda materia académica lleva implícito.

El segundo modelo tiene mucho que ver con lo que se apuntaba en el apartado denominado "Capitalización intensiva de propiedades" y que en última instancia justifica la disciplina por un supuesto valor intrínseco de la materia o de las actividades que la conforman; un valor indiscutido a cuyo reclamo se urde toda una red propiedades tan loables como indemostrable es que dichas propiedades no concurran de igual manera en actividades pedagógicas absolutamente diferentes o simplemente en la actividad cotidiana fuera del espacio 
de asistencia y tutelaje escolar. Se trata de aquellas propiedades que se ajustan muy bien al desiderátum de "merece la pena ser aprendido" pero cuyo resultado es difícilmente constatable y, sobre todo, es difícilmente constatable la influencia que la acción pedagógica específica -en este caso de la Educación Física- pudiera haber tenido en dicho resultado. Algo que no desacredita totalmente dicha acción pedagógica específica -si se considera que (casi) cualquier producto cultural puede ser valioso- pero sí anula el argumento por el que se pretende justificar la presencia obligatoria de la materia en la institución escolar. Porque dicha presencia exige, además de la valía cultural genérica, otras condiciones de pertinencia entre las que la practicidad ha de ocupar, parece, un lugar de privilegio.

Enlapráctica,ambosmodeloscomparten espacio y funcionan indistintamente entre los profesionales, con mayor énfasis en uno u en otro según el momento, las condiciones, el contexto o según el destinatario de las explicaciones -si es que se trata de explicar a alguien el porqué de la Educación Física-. Lo que llama la atención es que el discurso de las justificaciones de carácter extrínseco (el discurso de las justificaciones pragmáticas) ha ido perdiendo espacio a favor de las de carácter intrínseco (aquellas que tienden a legitimar la materia por el valor que posee en sí misma o por el valor íntimo de sus contenidos: juego, deporte, experiencia corporal, etc.). Y aunque el motivo de tal perdida de espacio suele achacarse a la aureola reaccionaria que tiene todo pragmatismo -lo cual hace buscar, por lo menos a los profesores más activos e innovadores, justificaciones de más "alto valor", razonamientos más complejos y más elaborados como los que se pueden arañar a la Filosofía, la Antropología o a cualquier disciplina de corte humanístico-, en la opinión de este autor, es una simple deriva argumental como consecuencia de la disolución de una practicidad obsoleta, poco atenta a las necesidades e intereses de la sociedad contemporánea y que la sátira de Benjamin (citado por Peddiwell, 1939) expresa de forma tan elocuente. Una practicidad anclada en necesidades e intereses viejos y escasamente representativos para muchos de los integrantes de las generaciones que forman la sociedad contemporánea unida a la secular resistencia institucional a prescindir de dichos contenidos e incorporar otros diferentes más acordes con las diversas realidades sociales y culturales. Resistencia a prescindir de dichos contenidos por ser considerados sustanciales, esenciales, naturales, intemporales, valiosos per se, lo que en gran medida sirve para encubrir o legitimar una posición conservadora e inmovilista -a la que seguramente se le suman motivaciones de carácter corporativista- mucho más reaccionaria que la practicidad a la que aquí se apela.

A este respecto, tal vez convenga precisar -aunque ya se esté muy avanzado este artículo- una cuestión de principios. Desde el punto de vista que se ha adoptado en este artículo, la practicidad como argumento justificativo de la pertinencia de una materia en la escuela no sólo no es reaccionario sino que es el único punto de apoyo sólido que permite legitimar la acción pedagógica que dicha materia implica. Otra cosa es qué elementos se consideran prácticos y cuáles no, bajo qué criterios se concibe la practicidad, con vista a qué clase de necesidades y, puesto que la población escolar no es homogénea, qué grupos se identifican con los patrones de practicidad interpuestos. Practicidad es atender las capacidades físicas y las habilidades que son necesarias para el desempeño eficiente en las prácticas lúdicas y de ocio o estéticas que demandan las clases acomodadas, si bien estas sean clasistas, y también es practicidad atender las capacidades físicas que son necesarias para un desempeño no subyugante en la vida laboral y doméstica. Por ejemplo, la de un transportista, la de una vendimiadora o de un estibador; es evidente que ambos criterios de practicidad dicen cosas muy diferentes acerca de cómo debería ser la Educación Física. En otros términos, es en la identificación de los intereses y en la selección de los contenidos y los medios apropiados para satisfacerlos donde 
cabe la discusión sobre si la practicidad es o no reaccionaria, si es clasista, si es sexista, etc. Es preciso aclarar a este respecto que practicidad -o funcionalidad práctica y utilitaria de la Educación Física- no significa asunción de las concepciones funcionalistas de la sociedad que se han comentado críticamente más arriba de acuerdo con lo que Mills (1999) denominaba practicidad liberal, conformista, acomodaticia y moralizadora, ni tampoco significa aceptación de los principios de eficiencia técnica de la razón instrumental y cuya producción monopolística, en nuestro caso de la motricidad, obedece a criterios de producción (del cuerpo) para el consumo y que el sociólogo norteamericano denominaba practicidad antiliberal, disciplinaria, controladora, autoritaria y economicista. Antes bien, constituye una apuesta por el sentido práctico de los aprendizajes corporales según criterios de producción (del cuerpo) para el uso propio, para el uso comunitario significativo y contextualizado, en todo caso, para un uso libre de las dependencias del consumismo del cuerpo; es decir, encaminados a la satisfacción de necesidades operativas comunes de gentes comunes en toda su diversidad: necesidades de destreza y habilidad simples pero útiles en la vida cotidiana, lejos de la hipertecnificación del ejercicio físico, lejos de la cinética corporal abstracta, burocratizada, sistemática y regular $\mathrm{y}$, asimismo, lejos de la institucionalidad de unas capacidades físicas racionalmente evaluables pero culturalmente desconectadas de la vida cotidiana para la mayoría. Constituye una apuesta, entonces, contra la exclusividad que suponen las prácticas corporales de clase, de cuyo contenido técnico o estético o ideológico se nutre el patrimonio distintivo la dominación cultural.

Así, en la medida en que el proyecto pedagógico implícito se oriente a la capacitación para el desempeño no solo de actividades simbólicas, recreativas, estéticas, etc., sino también y sobre todo a la capacitación doméstico-laboral y, asimismo, en la medida en que se dirija no a la perpetuación del sistema y sus desigualdades mediante la inculcación-reproducción de los modelos de acción hegemónica sino a la transformación social mediante el desarrollo de capacidades críticas, deliberativas, de innovación y transformación, igualitaristas, con respecto a los usos y consumos corporales, la intervención educativa resultará eminentemente práctica. A fin de cuentas, practicidad es también aplicar los recursos pedagógicos a las necesidades culturales de emancipación, individual o colectiva respecto de la presión que ejercen los usos y los valores de la cultura física dominante a menudo enunciados con términos de dudosa neutralidad moral e ideológica tales como autosuperación, autodominio físico, placer del movimiento, cuidado de sí mismo, etc. las cuales forman parte de la sensibilidad emergente de las clases urbanas acomodadas y de una relación del individuo con su cuerpo muy al gusto y conforme a los intereses de los miembros más consumistas de dichas clases.

A este respecto, volviendo a los tipos de justificación sobre los que se ha discutido, como complemento de las justificaciones intrínsecas ajenas a la denostada practicidad, tiene lugar, paradójicamente, una hipertrofia del discurso técnico. A falta de discusión -especialmente discusión ideológica, pero también a falta de discusión moral y práctica- sobre los criterios de selección de los objetivos educativos y sobre la utilidad de estos, dado el supuesto valor intrínseco de la acción físico-educativa y de los contenidos de esta, se ha desarrollado todo un conjunto de argumentos sustitutivos superficialmente técnicos que en la práctica funcionan como una creencia de corte dogmático: la creencia en la eficacia técnica de la didáctica amparada en la verosimilitud que reporta la relación mecánica entre medios y fines por muy endeble que sea, socialmente hablando, la operatividad o la practicidad de los fines. Más aún, la creencia según la cual dicha eficacia técnica -en el caso de ser ciertaagotaría el campo de las controversias pedagógicas de la materia. Es a esto a lo que se denomina el conocimiento pericial como 
creencia; elemento fundamental de la ilusión didáctica que, combinando los principios ideológicos de la racionalidad instrumental -los principios de la eficacia productiva no tanto para el uso como para el consumo especulativo- con los resortes emocionales del idealismo pedagógico, solo puede contribuir a disolver un debate mucho más perentorio en la Educación Física: el debate del sentido (cultural, ideológico y político) de la materia escolar y de los contenidos en los que instruye sea cual fuere la eficacia con la que lo hace.

\subsubsection{De la (supuesta) vastedad, suficiencia y neutralidad pedagógica del deporte}

Elconocimiento pericial comocreencia -la ilusión didáctica- es posiblemente algo compartido por buena parte de los maestros y profesores de muchas materias escolares y tal vez se puede convenir en que esto está fuertemente relacionado con el carácter vocacional que siempre han mostrado las profesiones de la enseñanza. Sin embargo, es preciso resaltar que el carácter vocacional que manifiestan los profesores de Educación Física se ha visto incrementado por la tradicional relación - a veces identificación- entre la Educación Física y la práctica deportiva y el hecho de que, desde hace bastantes décadas, todas las cohortes de ejercientes hayan estado nutridas mayoritariamente por deportistas de mayor o menor nivel de implicación y dedicación, pero cuyo vínculo emocional más que racional con el deporte ha determinado la inclinación profesional hacia la Educación Física. Dicho vínculo, que es innegable, puede explicar cómo el entusiasmo pedagógico en los profesores de dicha materia ha podido constituir también una cortapisa para la reflexión crítica sobre ella como materia escolar y un freno a la innovación metodológica, de contenidos y, sobre todo, un freno al análisis de la filosofía que informa y orienta los objetivos de la materia. En todo caso, una limitación a la comprensión amplia de la materia y sus significados alimentada, en parte, por la común propaganda institucional que ha llegado a encumbrar al deporte a la categoría de actividad física más importante de nuestra sociedad y para el que no dejan de proclamarse sus beatíficas virtudes moralizadoras y normalizadoras.

\section{De la (supuesta) vastedad y suficiencia pedagógica del deporte}

Tal vez, una de las más arraigadas creencias que mantienen los profesores de Educación Física -aunque no solamente ellos- sea la que tiene que ver con la vastedad de la experiencia corporal deportiva y la virtualidad educativa que por sí misma procuraría la acumulación de dicha experiencia corporal; una vastedad a la que, en ocasiones, se suma la idea de suficiencia. Se trata de la concepción recurrente de que la gran variedad de las especialidades deportivas -con la infinidad de técnicas corporales que dichas especialidades suponencontiene una gama tan grande de técnicas y de acciones corporales para los alumnos y las alumnas, así como de gasto calórico, que con la sola práctica del deporte se podrían cubrir todas las expectativas de desarrollo de habilidades y capacidades físicas. No cabe duda de que la práctica deportiva implica un compromiso exhaustivo del cuerpo: en la mayor parte de los casos un gran compromiso energético y muchas ocasiones un importante compromiso técnico, perceptivo, coordinativo y de toma de decisiones. Es en este tipo de argumentaciones en que la Educación Física trata de sostener un carácter eminentemente deportivo a lo que, en ocasiones, añade el papel formativo de la competición y de la autodisciplina que dicha competición impone.

Sin embargo, es necesario plantearse si el espectro de la motricidad que cubre la práctica de los deportes y el aprendizaje 
de sus técnicas, incluso si verdaderamente tuviera cabida en la escuela una amplia gama de especialidades -que no suele ser el caso por la evidente escasez de recursos espaciales, temporales, materiales y de formación del profesorado-, constituye o no un tipo de experiencia cuya capacitación tenga alcance más allá de la propia prestación deportiva. La opinión de este autor es que muy escasamente la tiene, que el carácter eminentemente abstracto de las técnicas deportivas supone grandes limitaciones formativas en aspectos tales como la creación, la expresión, la capacidad deliberativa, la introspección, la apreciación estética, etc. que a menudo figuran como estandarte de los objetivos de la Educación Física. Supone, muy especialmente, grandes limitaciones respecto del desarrollo de habilidades sociales en tanto que las relaciones que establece están muy determinadas por el antagonismo competitivo. Por otra parte, el tan alto grado de especialización y a menudo de automatización de la dinámica interna de las acciones deportivas deja escaso margen para que los aprendizajes deportivos tengan efectos prácticos significativos sobre las habilidades físicas y no físicas que los sujetos de la acción pedagógica requerirán en la vida cotidiana. A este respecto, la teoría de la transferencia motriz parece sólo una coartada destinada a mantener el estatus pedagógico de unas prácticas que de otro modo serían consideradas escasamente formativas incluso cuando el deporte se auspicia bajo el subterfugio del juego.

\section{De la (no) neutralidad ideológica y pedagógica del deporte}

No sería posible mantener la creencia que se ha denominado como vastedad y suficiencia pedagógica del deporte si este no se hubiera hecho acreedor de los más altos valores culturales aplicándole virtudes no sólo formativas sino que, muy especialmente, propiedades reformativas: enmienda para transgresores, moral para amorales, correctivo para delincuentes, revulsivo para vagos, pedagogía para inadaptados, etc. además de medicina para enfermos y entretenimiento para aburridos. No sería posible mantener dicha creencia si, como ya se ha dicho, no hubiera sido elevado a la categoría de actividad física más importante de nuestro tiempo, de nuestra sociedad y de nuestra cultura; como si nuestro tiempo, nuestra sociedad y nuestra cultura fueran homogéneos y en su interior no hubiera ni sensibilidades diversas, ni intereses diferentes, ni expectativas divergentes, el deporte se presenta como elemento transversal a todas las clases sociales, a todas las ideologías, a todos los credos, a todas las variedades étnicas y culturales, a todos los géneros, etc. de manera que queda infundido de esa naturaleza sustancial y universal de la que se hablaba más arriba y, sobre todo, de una neutralidad ideológica, política y cultural que lo hace indiscutible. Sin embargo, si, como se ha argumentado, ninguna práctica corporal existe de manera independiente de los gustos y de las propias necesidades de clase -0 de cualquier otro grupo social- en cuyo seno aparece y a cuyos intereses responde; entonces el deporte ha de constituir alguna clase de ideología particular bajo la cual se configuran las distintas prácticas no sin el libramiento de permanentes luchas simbólicas entre distintos grupos sociales que pugnan socialmente por imponer y consolidar una forma concreta de entender la realidad social y el propio deporte dentro de ella. Una ideología que necesariamente opera como dispositivo de legitimación cultural al servicio de los intereses (culturales, sociales, económicos, etc.) de los grupos dominantes: la clase dominante, la etnia dominante, el género dominante.

No es esta la ocasión para extenderse en la crítica a la ideología deportiva, pero sirva sugerir una reflexión sobre el tipo de valores que supone y enseña la competición deportiva así como el camino 
para llegar a ella: el entrenamiento intensivo, la renuncia ascética, la selección metódica y permanente; cierto cultivo del individualismo, no sin importantes dosis de agresividad, acompañado de lo que se ha dado en denominar el papel educativo del ídolo deportivo y que, desde el punto de vista planteado aquí, constituye una modalidad pedagógica que lejos de fomentar el sentido crítico, la autonomía o la creatividad, etc. inculca el modelo social de las adhesiones incondicionales, del aprendizaje por imitación, de la ensoñación alienante de la gloria de otros, del culto al éxito y a la apariencia, etc. Los modelos deportivos, en cualquiera de sus facetas, no se distinguen ni por tener estructuras democráticas ni un modo de funcionamiento igualitarista; más bien, se caracterizan por la verticalidad de sus estructuras, las cuales se imponen como requisito de las relaciones de autoridad que otorgan legitimidad a formas abiertas de discriminación como, por ejemplo, las de género-que en otros ámbitos se combaten por inaceptables- y a formas de discriminación no tan abiertas pero igualmente inadmisibles como las de clase o de etnia.

Repárese, por otro lado, en el sentido del deporte recreativo cuya filosofía encarna perfectamente los valores de la burguesía urbana, los valores de la burguesía acomodada, satisfecha y ociosa: los valores en torno a la salud, la belleza, la recreación, el trabajo, la alimentación, etc. de la clase dominante en aras del sostenimiento de la cultura dominante; de donde la extensión hacia abajo del deporte por medio de la difusión (también escolar) de especialidades proletarias cabe interpretarse no como el resultado de un proceso de democratización de las prácticas corporales, sino de una colonización cultural e ideológica selectiva ${ }^{3}$ que debería llamar la atención sobre las verdaderas funciones de los contenidos deportivos en la Educación Física.

Se debería preguntar, a modo de ejemplo, por el sentido que tiene la articulación de la Educación Física en la liturgia deportiva: el empleo del uniforme deportivo, el calentamiento, los materiales, los espacios, la propia conceptualización y catalogación de las cualidades que ella dice desarrollar; se debería preguntar por el sentido que tiene, en general, la modalidad del control vigilante que exhibe el ritual del ejercicio físico.

\subsection{La experiencia corporal como pretexto}

Evidentemente, las sensibilidades pedagógicas en torno a la Educación Física no se limitan en exclusiva a las que la enseñanza del deporte determina ni al desarrollo de capacidades y aptitudes definidas por lo deportivo, aunque estas sigan siendo hegemónicas. Muchas de las iniciativas denominadas innovadoras o alternativas han puesto sobre la mesa contenidos hasta hace poco escasamente relevantes en el conjunto curricular de la materia, y algunas de ellas han encontrado refrendo, incluso, en disposiciones normativas que, al menos en la letra, abogan por una Educación Física más allá del deporte, en aras de una formación corporal plural y diversa dando cabida, por ejemplo, a las actividades artísticas del cuerpo y expresivas en general. Nociones como cuerpo simbólico, cuerpo expresivo y comunicativo unidas a la bien arraigada idea de necesidad funcional de movimiento han ido otorgando relevancia a la categoría pedagógica de la experiencia corporal que ha permitido ir más allá del corto alcance que pudiera tener el dominio de una técnica corporal concreta -deportiva o no-, y también más allá de la provisionalidad de la capacidad orgánica desarrollada. Todas ellas han contribuido a modificar algunos de los más acendrados presupuestos de la educación tradicional, hasta el punto de que no parece que ningún discurso sobre la materia pueda prescindir hoy de la justificación que constituye la necesidad de experiencia corporal.

Sin embargo, dicha necesidad, indiscutible por lo genérica y ambigua, sirve para interponer prácticas y para producir 
aprendizajes cuyos valores culturales y prácticos concretos pueden ser de muy distinta condición y, por lo tanto, de muy diferente significado; desde la práctica de libre juego hasta la carrera extenuante pasando por la danza, el deporte, el aprendizaje de una técnica manufacturera o la no práctica, todas proporcionan experiencia corporal pero, como ya se ha apuntado, imprimen signos muy distintos en la subjetividad y configuran modelos corporales también muy distintos. De donde dicha noción de experiencia enunciada en abstracto termina apelando solo a un requerimiento acumulativo de "movimiento", de actividad física, donde lo que menos parece importar es la adscripción cultural que cada experiencia corporal concreta lleva implícita.

No se puede perder de vista que toda experiencia corporal constituye una modalidad cultural de comprensión del cuerpo propio y de su relación con el mundo y con los demás; es un espacio de producción simbólica e ideológica, tanto más en la medida en que su administración pedagógica determina una clase, un tipo de experiencia corporal que probablemente no todos deseen, de la que no todos disfrutan, que no sirve a todos ni a todos es significativa existencialmente, lo que puede constituirse como la agresión simbólica y a menudo física que muchos realmente sienten. Por añadidura, al servir de apoyo y justificación de la materia escolar, la experiencia corporal tiende a invalidar todo otro modo relacional y de experiencia con el cuerpo: especialmente los modos no dominantes y sobre todo los no escolásticos de tratamiento de la corporeidad y del gesto. Aquí la ilusión didáctica consiste en primer lugar en la creencia de que toda experiencia corporal por el hecho de poner al cuerpo en movimiento y producir sensaciones, intelecciones o emociones es deseable; y, en segundo lugar, que el saber pericial es capaz de determinar técnicamente la forma y modalidad de administración de la experiencia corporal de modo que sea de interés para el sujeto, sin contar con los sujetos de la acción pedagógica o contando solo retóricamente y en genérico con el "sujeto".

Si se tiene en cuenta que los cuerpos no son nunca espacios libres; que son lugares en los que se inscriben las marcas culturales organizando los actos y los afectos y que históricamente tales inscripciones han operado como regulaciones prácticas al servicio del régimen dominante de la cultura, entonces qué otro sentido que el funcional y técnico se puede encontrar en los distintos elementos de la liturgia pedagógica del cuerpo. ¿Qué sentido y qué significación tienen, por ejemplo, el uso del chándal, las zapatillas deportivas, el calentamiento, la ceremonia del ejercicio y tantos otros elementos rituales que conforman la puesta en escena de la Educación Física escolar? Por encima de la funcionalidad declarada que todos ellos poseen, constituyen individualmente y en conjunto un signo; este tomado en gran medida del código de las formas deportivas en cuyo interior adquiere su pleno sentido. Por encima de la "comodidad y libertad de movimientos" que reporta el atuendo deportivo, por encima de la "seguridad" que reportan las zapatillas deportivas, por encima de la "funcionalidad fisiológica" del calentamiento, etc., la escenificación de todo ello constituye, no se puede negar, una expresión de los principios que informan la Educación Física escolar y que comúnmente se aceptan. Lo mismo se puede decir del sentido y significación del paisaje escolar cuyos patios y gimnasios se adornan indefectiblemente con el consabido aparataje deportivo; asimismo, de la porción seleccionada de los contenidos y hasta de la propia conceptualización y catalogación de las cualidades que la Educación Física trata explícitamente de desarrollar mediante la experiencia corporal que facilita.

Lo que se está planteando es que frecuentemente la experiencia del movimiento pedagógicamente administrada es un exponente ideológico de la sensibilidad dominante. Con gran probabilidad (sociológica), los principios y valores que la 
conforman no serían sino los principios y valores de una fracción con capacidad para proponer e imponer su propio estilo de vida y en cuyo vértice se sitúa la estrategia por la cual se trata de convencer y de convencerse de la necesidad de someterse a un proceso de acondicionamiento que es sobre todo un proceso de entrega a la mirada pericial del profesor bajo la ensoñadora ilusión de que este, al igual que el agricultor separa el grano de la paja, hace distinguir entre la buena y la mala práctica ofreciendo a sus alumnos solo aquello que está pedagógicamente contrastado: relación de poder que se cierne inevitablemente sobre ese espacio privado e íntimo que es el cuerpo propio. Relación de poder que lo es más en cuanto que, como toda acción pedagógica, pretende perpetuarse como mirada, más allá de la inmediata observación física que se da en ese tiempo y en ese espacio institucional que es la escuela con el objeto de asegurar la eficacia de la experiencia: una adherencia casi constitutiva a los modos en que corporalmente se debe ser, hacer, sentir. Los motivos por los que se debe sufrir y disfrutar, o sea, las formas legitimadas de la corporalidad.

Muchas de las justificaciones pedagógicas de la Educación Física han encontrado raíz y respaldo en las modernas teorías psicobiológicas del desarrollo y la importancia que estas conceden al movimiento corporal en casi todos los órdenes. No se discute en este sentido que el movimiento es necesario por más que favorezca o no la inteligencia (creencia que merecería un amplio debate), pero la justificación de la Educación Física en este dominio da un salto en el vacío, y de la necesidad del movimiento deduce la imposición del ejercicio físico. Que el movimiento sea necesario no implica que lo sea el ejercicio físico ni ninguna modalidad cultural en la que este se proyecta; en todo caso, no implica que sea necesaria su escolarización reducida a un proceso de modulación del desarrollo orgánico que encarna un sistema destinado al fin y al cabo a crear consumidores, competidores y contribuyentes satisfechos.

\section{A modo de conclusión}

Como reflexión conclusiva póngase de relieve los intentos innovadores y transformadores que muchos profesores e incluso algunas legislaciones han ido poniendo en marcha en las últimas décadas. Es evidente que el conjunto de estas ha transformado en el medio plazo la materia académica y, con ella, el sentido de los aprendizajes corporales escolares. Sin embargo, desde una perspectiva amplia y de largo plazo, tales cambios admiten una lectura algo más pesimista que aquella que trata de proyectar el pedagogo idealista; tales cambios han de verse también como una reacción estratégica de dominación ante los nuevos retos que tienen ante sí las clases dominantes. Serían cambios que, parafraseando a Foucault, se imponen para responder a exigencias de coyuntura pero que en conjunto se inscriben en el proceso de mutación general de administración disciplinaria.

A este respecto, indagar en los procesos de configuración de la Educación Física, incluso si auspiciara un debate abierto y generalizado sobre los mecanismos de legitimación de los contenidos, los objetivos, los métodos y la propia filosofía de la disciplina -como el aquí se ha planteado-, no es ninguna garantía de transformación. Según se apuntaba al principio, en la historia de la Educación Física de nuestro entorno tal vez no se ha vivido otra época de ebullición crítica teórico-práctica como la de las tres últimas décadas y, sin embargo, el tipo de cambios experimentados por la disciplina no pasan de ser leves y banales adaptaciones técnicas a los dictados de la moda que poco tienen que ver con los propósitos, a menudo enunciados, de significatividad de los aprendizajes corporales, emancipación, desarrollo del sentido crítico respeto a la diversidad cultural, aminoración de las desigualdades, etc. Son cambios que, desde el punto de vista aquí planteado, tienen poco que ver con el desarrollo de la apreciación crítica de los usos diversos del cuerpo en una sociedad como la nuestra en la que 
el saber legitimo -y acomodado- exalta el cuerpo deportivo, el cuerpo lúdico, el cuerpo en forma, el cuerpo bello, etc., tal como lo perciben o lo sueñan las clases con capacidad para construir y difundir discursos y prácticas deportivas, lúdicas, de la forma física o de la belleza.

Sin embargo, no se puede esperar a que la imparable fagocitación del pensamiento crítico por parte de los saberes técnicos y el conocimiento legitimado termine por invisibilizar a aquellos que en los procesos sociales de distribución de los recursos materiales y simbólicos para el uso del cuerpo han ido quedando en los márgenes de la cultura física legítima; tampoco se debe esperar a que las bienintencionadas ilusiones pedagógicas de la sociedad bienpensante ahoguen las oportunidades reales para la igualdad mediante la aplicación formal y neutra de un inicuo procedimiento de igualdad de oportunidades que sigue descansando en la creencia de que el conocimiento que dispensa la escuela es neutro y su adquisición no tienen nada que ver con la clase social, la etnia-cultura, el género, etc.; algo que es especialmente relevante en el caso de la Educación Física, en la que las concepciones dominantes sostienen que el cuerpo es algo naturalmente dado. No se puede esperar, entonces, que análisis de esta clase provoquen un cambio sustancial pero sí se debe contemplar como posibilidad, al menos, que el paulatino desvelamiento de los mecanismos de legitimación del conocimiento técnico que sustenta la Educación Física escolar contribuya a evidenciar el problema de modo que los conflictos en torno al uso y la imagen del cuerpo no se encubran al traspasar la puerta del gimnasio escolar; se debe ayudar a que el conflicto ideológico y político que supone intervenir en el cuerpo -en los cuerpos- y en sus aprendizajes no se disuelva, por saturación de la racionalidad instrumental y de las nociones funcionalistas que alberga, en un mero problema de ingeniería didáctica.

\section{Notas}

1 Esta cuestión la plantean Berger y Luckmann (2003, p. 33) de modo exquisito al considerar, en torno a la sociología del conocimiento, las alternativas weberiana y durkheiminana en torno a las categorías objetivo-subjetivo, desde su punto de vista, no contradictorias: que las instituciones posean una facticidad objetiva -que diría Weber- y que estén construidas por una actividad que expresa un significado subjetivo -que diría Durkheim-, sólo manifiesta, señalan estos autores, una dualidad "sui géneris" de la sociedad que, en todo caso, insinúa una cuestión a la sociología del conocimiento: ¿cómo es posible que los significados subjetivos se vuelvan facticidades objetivas? o, ¿cómo es posible que la actividad humana produzca un mundo de cosas?

2 Seres cuya esencia consiste en la no existencia; tomados de la mitología popular e historietas infantiles.

3 Los deportes de las clases no dominantes sólo comparten algunas características con respecto a los deportes burgueses y de las elites: aquellos, de acuerdo con los modelos de actividad laboral del proletariado, se constituyen como una extensión y afianzamiento de las condiciones de trabajo mediante prácticas en las que predominan la fuerza, la resistencia, el desgaste físico en general, frente a prácticas más simbólicas, comunicativas, introspectivas que caracterizan a los deportes de las clases dominantes.

\section{Referencias bibliográficas}

Berger, P. T., y Luckmann, T. (2003). La construcción social de la realidad. Buenos Aires: Amorrortu.

Bourdieu P. (1988). La distinción. Criterio $y$ bases sociales del gusto. Madrid: Taurus.

Elias, N. (1978). What is sociology? [¿̇Qué es sociología?] Londres: Hutchinson.

Elias N. (1989). El proceso de la civilización. Madrid: Fondo de Cultura Económica. 
Elias, N. (1990). La sociedad de los individuos. Barcelona: Península.

Foucault, M. (1979). Vigilar y castiga. Nacimiento de la prisión. Barcelona: Siglo XXI.

Foucault, M. (1999). El orden del discurso. Barcelona: Tusquets.
Mills, W. C. (1999). La imaginación sociológica. Madrid: Fondo de Cultura Económica.

Peddiwell, J. A. (1939). The saber-tooth curriculum [El curriculum dientesde-sable]. Nueva York: McGraw-Hill.

Wittgenstein, L. (1994). Los cuadernos azul y marrón. Barcelona: Planeta. 